FELIPE RODOLFO DE CARVALHO

\title{
OUTRAMENTE: \\ O DIREITO INTERPELADO PELO ROSTO DO OUTRO
}

\author{
Tese de Doutorado \\ Orientador: Professor Associado Eduardo C. B. Bittar
}

UNIVERSIDADE DE SÃO PAULO

FACULDADE DE DIREITO

São Paulo-SP

2017 


\section{FELIPE RODOLFO DE CARVALHO}

\section{OUTRAMENTE:}

\section{O DIREITO INTERPELADO PELO ROSTO DO OUTRO}

Tese apresentada à Banca Examinadora do Programa de Pós-Graduação em Direito da Faculdade de Direito da Universidade de São Paulo, como exigência parcial para obtenção do título de Doutor em Direito, na área de concentração Filosofia e Teoria Geral do Direito, sob a orientação do Professor Associado Eduardo C. B. Bittar.

UNIVERSIDADE DE SÃO PAULO

FACULDADE DE DIREITO

São Paulo-SP 



\section{AGRADECIMENTOS}

Ao Prof. Eduardo Bittar, por ser Mestre e Orientador, pela excepcional acolhida, pelo constante acompanhamento, pela inesgotável preocupação.

Ao meu irmão, Luciano, razão deste trabalho, que, sem que eu entenda, soube entender que eu estava distante, mas próximo, no "estudo".

Aos meus pais, pelo amor, pelo apoio e pelas orações.

Aos meus amigos de Cuiabá e aos que aqui em São Paulo fiz, em especial o Ricardo, a Talitha e o André.

Aos membros da minha banca de qualificação, Prof. Luiz Paulo Rouanet e Prof. Franklin Leopoldo e Silva, por terem acreditado no meu trabalho e pelas contribuições.

Aos membros da minha banca de defesa, por aceitarem o convite e pela generosidade de participar da sua construção.

A Deus. 
Para Luciano. 
O senhor disse a Caim: "Onde está seu irmão Abel?" - Caim respondeu: "Não sei! Sou porventura o guardião do meu irmão?" (Gênesis 4:9) 


\section{RESUMO}

Felipe Rodolfo de Carvalho. Outramente: o direito interpelado pelo rosto do Outro. 2017. 461. Doutorado - Faculdade de Direito, Universidade de São Paulo, São Paulo, 2017.

Num quadro histórico de desarticulação do fenômeno jurídico, mas também de uma procura renovada pelo seu sentido, este trabalho procura re-pensar o direito outramente. A tese que defende é a de um direito enquanto resposta, e a da sua positividade enquanto responsabilidade - responsabilidade em face de um rosto, o rosto do Outro, que o interpela. Organizada em quatro partes, busca, na primeira, explicitar a formação do direito na modernidade enquanto um direito pautado no Eu e os resultados desastrosos daí provenientes; na segunda, procura descrever o momento de crise do direito na pós-modernidade como ocasião propícia à reformulação do seu sentido, invocando o pensamento de Emmanuel Levinas como um referencial que permite compreender o jurídico à luz do Outro; na terceira, propõe-se a examinar temas atuais, como o dos "direitos humanos", o do "reconhecimento", o da "igualdade e diferença" e o da "dignidade da pessoa humana", a partir da ótica levinasiana; na quarta, debruça-se sobre a realidade jurídica brasileira contemporânea para nela encontrar a manifestação concreta das várias faces do Outro.

Palavras-chave: direito; rosto; Outro; alteridade; Emmanuel Levinas. 


\section{RÉSUMÉ}

Felipe Rodolfo de Carvalho. Autrement: le droit interpellé par le visage de l'Autre. 2017. 461. Doctorat - Faculté de droit, Université de São Paulo, São Paulo, 2017.

Dans un contexte historique de désarticulation du phénomène juridique, mais aussi d'une recherche renouvelée de son sens, ce travail cherche à ré-penser autremente le droit. La thèse qu'il défend, c'est celle du droit comme réponse, et celle de sa positivité en tant que responsabilité - la responsabilité devant un visage, le visage de l'Autre, qui l'interpelle. Organisé en quatre parties, la thèse cherche, d'abord, à expliquer la formation du droit dans la modernité comme un droit basé sur le Moi et ses résultats désastreux; dans la deuxième partie, la thèse cherche à décrire le moment de la crise du droit dans la postmodernité comme une occasion propice à la reformulation de son sens, en invoquant la pensée d'Emmanuel Levinas comme référence qui permet de comprendre le droit à la lumière de l'Autre; dans la troisième, ce travail propose d'examiner les thèmes actuels tels que «droits de l'homme», «reconnaissance», «égalité et différence» et «dignité de la personne humaine» du point de vue lévinassienne; dans la quatrième, il regarde la réalité juridique brésilienne contemporaine pour y trouver la manifestation concrète des divers visages de l'Autre.

Mots-clés: droit; visage; Autre; alterité; Emmanuel Levinas. 


\begin{abstract}
Felipe Rodolfo de Carvalho. Otherwise: the law interpellated by the face of the Other. 2017. 461. Doctorate - Faculty of Law, University of São Paulo, São Paulo, 2017.

In a historical context of disarticulation of the legal phenomenon, but also of a renewed search for its meaning, this work seeks to re-think the law otherwise. The thesis that it defends is the thesis of the law as responsibility, and its positivity as responsibility - responsibility before a face, the face of the Other, wich interpelates it. Organized in four parts, it seeks, first, to explain the formation of law in modernity as based on the Self and the disastrous consequences that comes from this situation; in the second, it seeks to describe the moment of crisis of law in postmodernity as a propitious occasion for the reformulation of its meaning, invoking the thought of Emmanuel Levinas as a reference that allows to understand the legal in the light of the Other; in the third, it proposes to examine current themes such as "human rights", "recognition", "equality and difference" and "dignity of the human person" from a levinasian perspective; in the fourth, it looks at contemporary Brazilian juridical reality in order to find in it the concrete manifestation of the various faces of the Other.
\end{abstract}

Keywords: law; face; Other; alterity; Emmanuel Levinas. 


\section{SUMÁRIO}

I- A MODERNIDADE E O “EU”: O NASCIMENTO DO SUJEITO DE DIREITO 17

1. A modernidade e o projeto do "Eu" 19

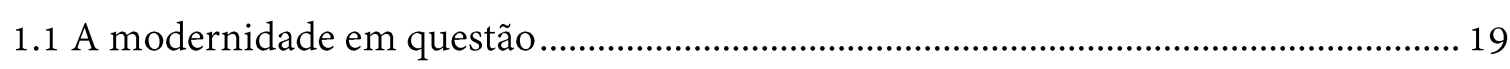

1.2 A ruptura temporal e a instauração do novo............................................................... 19

1.3 A subjetividade fundadora do conhecimento: Descartes e o Eu pensante..................... 26

1.4 A subjetividade moral autônoma: Kant e o Eu transcendental ...................................... 35

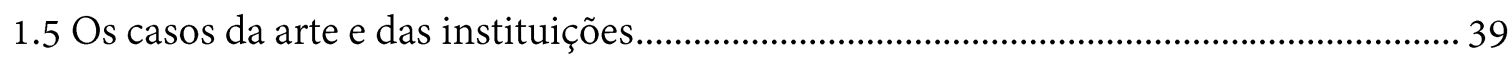

1.6 Modernidade, totalidade e ambivalência....................................................................... 40

2. O direito e a despersonalização/desconsideração do "Outro" _ 43

2.1 No começo, era o meu direito ............................................................................................ 43

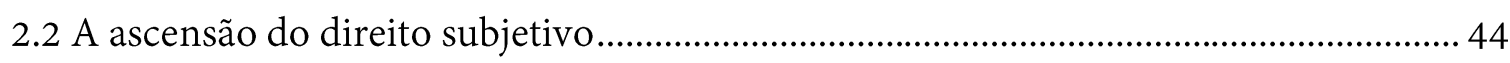

2.3 A fundação do direito em Hobbes: o estado de guerra, o medo da morte e o interesse esclarecido.

$2.4 \mathrm{O}$ controle jurídico do tempo .................................................................................................. 55

2.5 A emergência da subjetividade jurídica e a despersonalização do eu e do Outro ....... 60

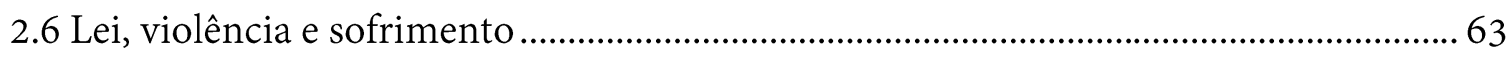

2.7 Responsabilidade sem fardos: a relação entre direito e moral ......................................... 64

2.8 Totalidade e exterioridade: a conversão de pessoas em papeis sociais ...........................66 66

3. A teoria do direito de Kant e seu papel na consolidação do modelo jurídico pautado no "Eu" 72

3.1 A repercussão da filosofia de Kant no direito .......................................................... 72

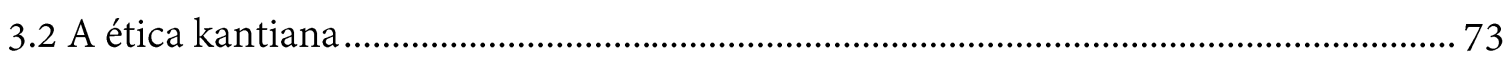

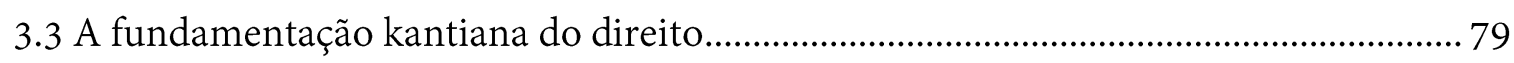

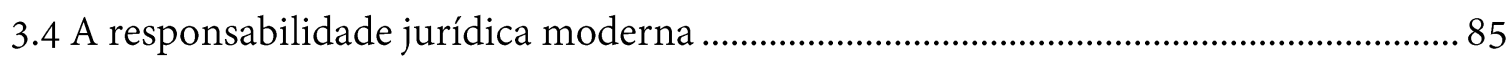

$3.5 \mathrm{O}$ sujeito de direito e seu paradoxo........................................................................................ 91

3.6 O direito subjetivo e a construção do espaço jurídico da indiferença ........................... 97

4. A teoria do direito de Kelsen e seu papel na consolidação do modelo jurídico pautado no "Eu" 100

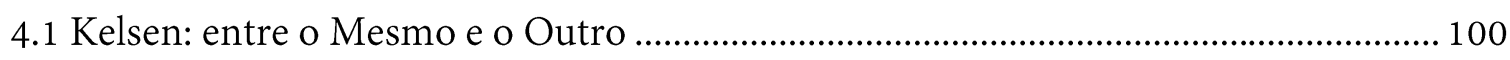

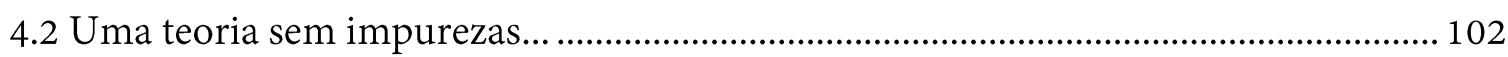

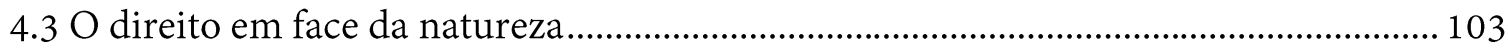

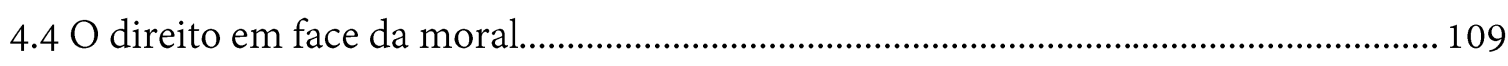

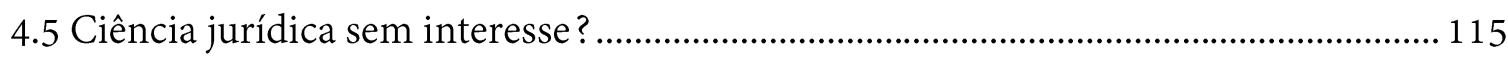


4.6 A negação do direito como condição do direito 118

4.7 O desaparecimento do homem no interior da ciência e o direito como um universo de normas

4.8 A identidade do sistema jurídico: a validade como critério distintivo entre o Mesmo e o Outro. 127

4.9 A norma fundamental como norma jurídica da indiferença. 133

5. O “Eu” moderno e a destruição do "Outro": excessos e retrocessos 138

5.1 Da totalidade à desagregação. 138

5.2 As guerras e a catástrofe do século XX 139

5.3 A destruição do Outro. 143

5.4 A filosofia do hitlerismo 152

5.5 A desumanização do homem 157

5.6 O sofrimento do Outro homem e o despontar de uma nova humanidade. 161

II- A PÓS-MODERNIDADE E A EMERGÊNCIA DO “OUTRO": DIREITO E ALTERIDADE 167

1. A inquietude do "Outro" na pós-modernidade 169

1.1 A totalidade estilhaçada e a pulverização de liberdades absolutas 169

1.2 Consumir para aliviar o tédio. 175

$1.3 \mathrm{O}$ desejo do Outro para além do desejo do consumo. 177

1.4 A má-consciência como consciência de crise 179

1.5 A inquietação no tempo: a inquietude do Eu e a inquietude do Outro 180

1.6 O sentido ético da crise pós-moderna: a irrupção traumática do Outro 182

1.7 O tempo das diferenças: o fim da teodiceia como face ética do fim das grandes narrativas 185

1.8 O Outro: uma nova orientação para o humano........................................................ 190

1.9 Maio de 1968 e o despertar de uma juventude responsável pelo Outro 193

1.10 Uma modernidade além da modernidade. 197

2. Repensar o direito pós-moderno a partir do "Outro": a contribuição de Emmanuel Levinas 200

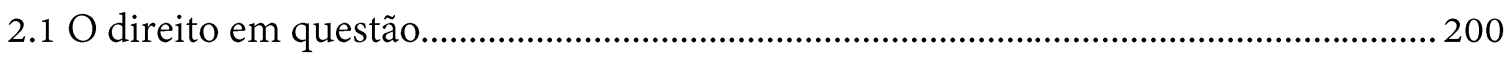

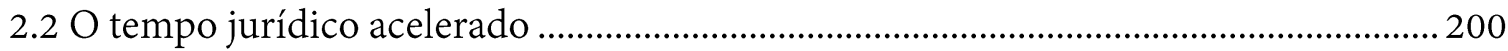

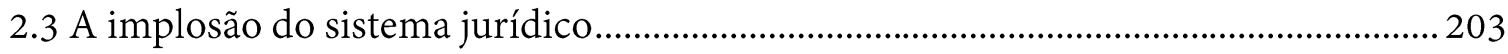

2.4 A conversão de um direito ineficaz num direito profundamente interrogado .......... 209

$2.5 \mathrm{O}$ sentido ético da crise do direito na pós-modernidade................................................2 214

2.6 Emmanuel Levinas e sua proposta de re-etização do fenômeno jurídico .....................217

2.7 A extravagante hipótese levinasiana. 220

3. Uma nova fundamentação para o direito: o "rosto do Outro" como ponto de partida225 
3.1 Um convite.

3.2 O problema do método em Emmanuel Levinas: a inefabilidade da experiência ética 225

3.2.1 Como dizer a alteridade? 225

3.2.2 Fundamento e anarquia 227

3.2.3 O método enfático 227

3.2.4 A redução filosófica: dizer, desdizer, dizer outramente 229

3.2.5 Reconstrução? 230

3.3 O momento pré-original: a constituição da subjetividade a partir da alteridade...... 232

3.3.1 O encontro com o rosto do Outro: o surgimento de um Dizer anterior ao Dito 232

3.3.2 A subjetividade como Dizer 234

3.3.3 A subjetividade como corpo sensível, vulnerável e animado 236

3.3.4 A subjetividade tecida na proximidade e interpelada à responsabilidade 240

3.3.5 A subjetividade refém que se realiza na substituição 246

3.4 A irrupção do terceiro: o surgimento do direito.............................................................2. 249

3.4.1 O salto do ético ao jurídico 249

3.4.2 A entrada do terceiro na situação ética e a necessidade da instauração de uma ordem jurídica justa 250

3.4.3 Legalidade e legitimidade___ 252

3.4.4 O tempo jurídico _ 254

3.4.5 A decisão jurídica___ 255

3.4.6 Um Estado liberal e democrático __ 257

3.4.7 O papel do estudo para o aprimoramento das instituições ___ 259

4. O caráter único e insubstituível da pessoa humana: proteção do direito e lugar da diferença 261

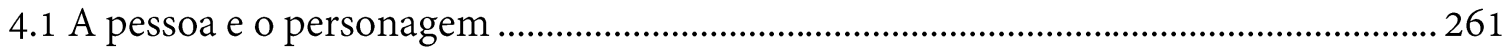

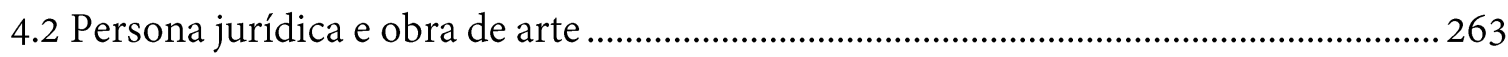

$4.3 \mathrm{O}$ entretempo da subjetividade jurídica...........................................................................265

4.4 O rosto para além da máscara da personalidade jurídica ...............................................2.268

4.5 O direito e o lugar da pessoa humana ...................................................................................2. 269

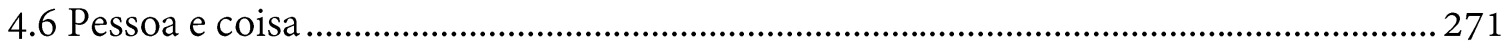

4.7 A diferença absoluta do Outro: unicidade e insubstituibilidade .................................. 274

4.8 A diferença absoluta do eu: unicidade e insubstituibilidade ...........................................2. 276

4.9 A defesa da pessoa humana como ato de resistência ao enrijecimento do direito.... 281

4.10 A obliteração do ordenamento jurídico pela inscrição da pessoa humana................283

III- A DIGNIDADE DE TODOS E DE CADA UM: O “OUTRO” E OS DIREITOS HUMANOS

1. A alteridade do "Outro" na cultura dos direitos humanos _ 287

$1.1 \mathrm{O}$ "triunfo" dos direitos humanos na pós-modernidade 
1.2 Direitos humanos e trivialização. 289

$1.3 \mathrm{O}$ "Homem" dos direitos humanos, seus direitos e sua cultura jurídica 292

1.4 Os direitos humanos em questão: do problema da inefetividade à pergunta pelo seu sentido. 298

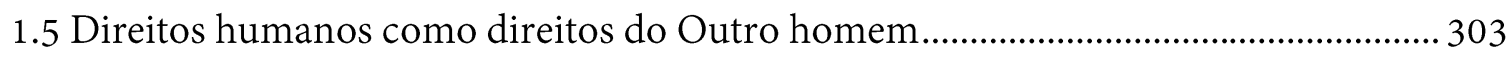

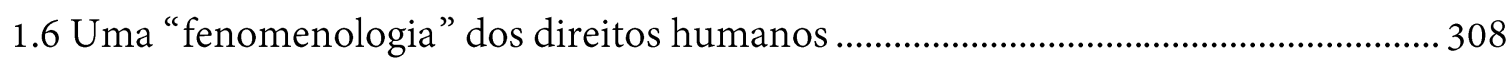

$1.7 \mathrm{O}$ "Outro homem" dos direitos humanos, seus direitos e sua cultura jurídica.......... 312

2. A alteridade do "Outro" na luta pelo reconhecimento: o direito à diferença __ 325

2.1 Ética da responsabilidade, ótica do reconhecimento ...................................................... 325

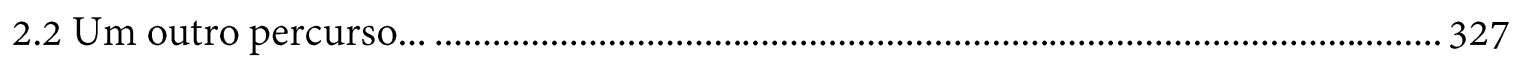

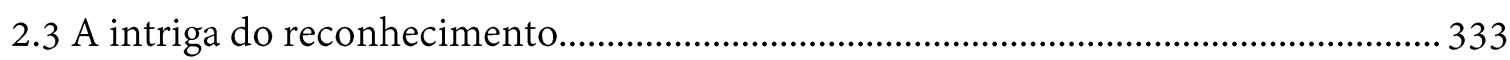

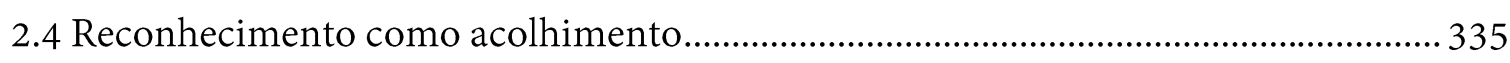

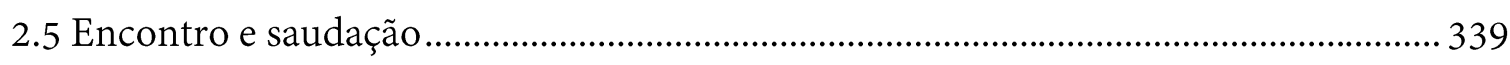

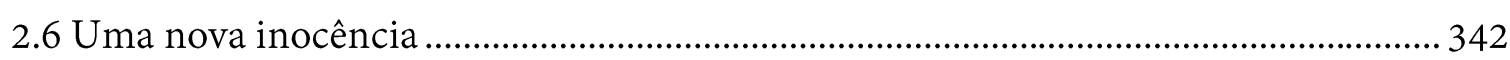

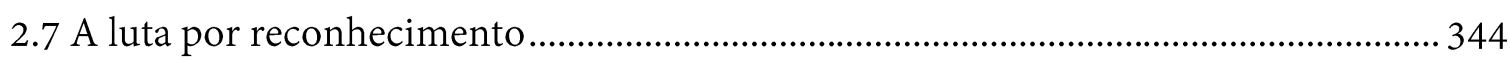

3. Os lugares da igualdade e da diferença: o " $\mathrm{Eu}$ " e o "Outro" na cultura dos direitos humanos_ 351

3.1 Da igualdade à diferença: o desafio da pós-modernidade .............................................. 351

3.2 Levinas: filósofo da diferença... e da igualdade .................................................................. 353

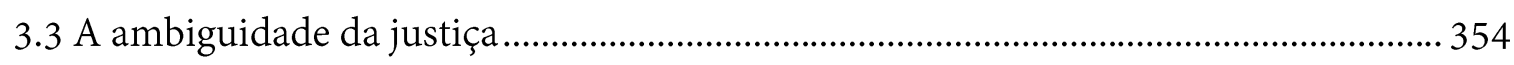

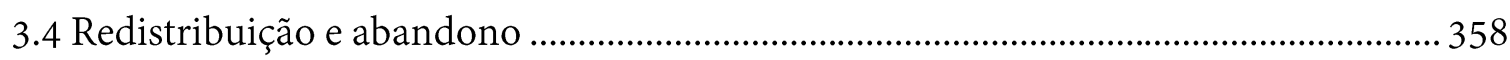

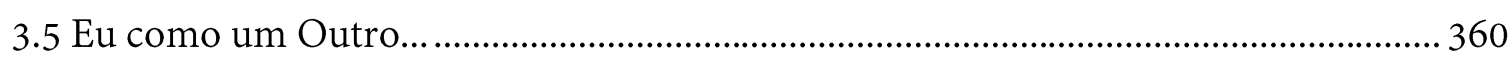

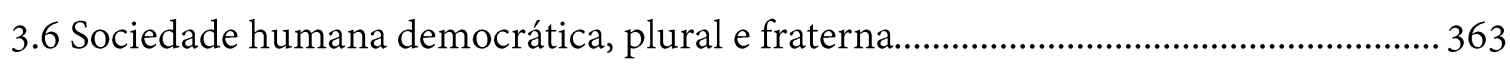

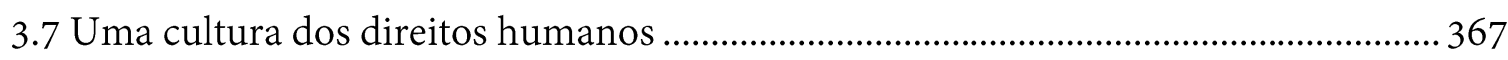

4. A dignidade da pessoa humana e sua fundamentação filosófica: a contribuição de Emmanuel Levinas _ 370

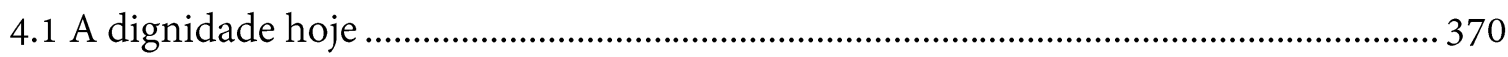

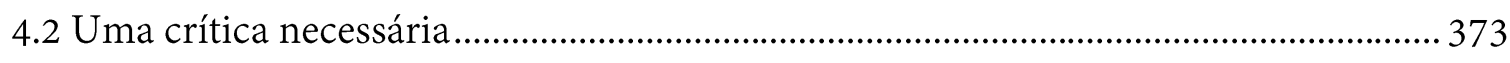

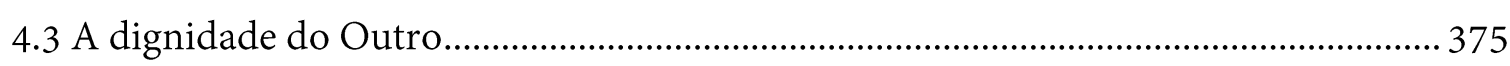

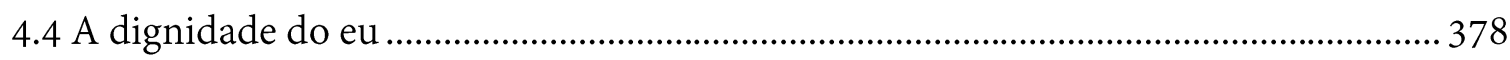

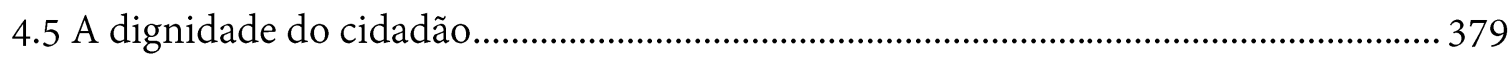

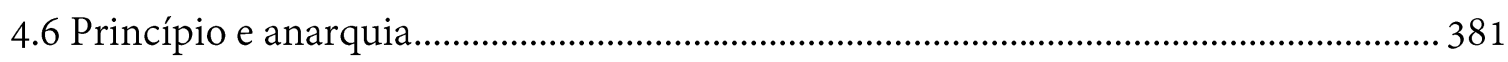

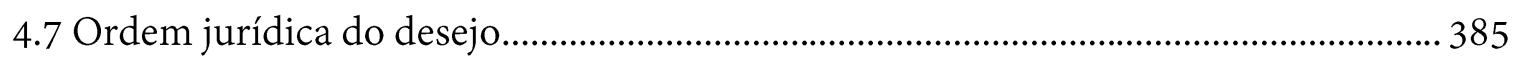

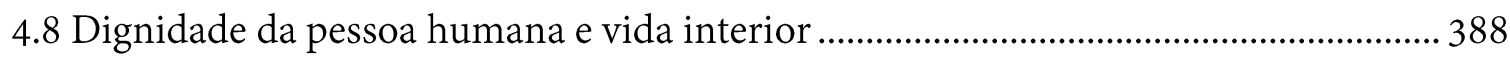

IV- AS VÁRIAS FACES DO “OUTRO” NA REALIDADE JURÍDICA BRASILEIRA CONTEMPORÂNEA 391 
1. O "Outro" na realidade jurídica brasileira: do encobrimento do rosto à multiplicação das suas faces

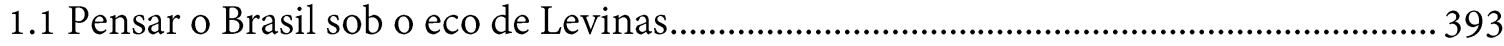

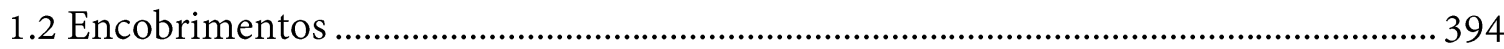

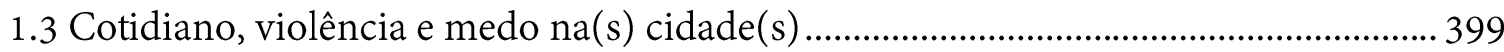

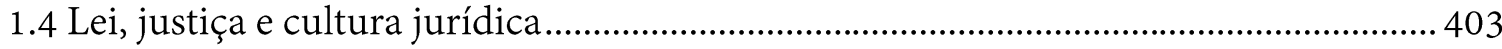

$1.5 \mathrm{O}$ direito à diferença e as novas legislações ........................................................................ 410

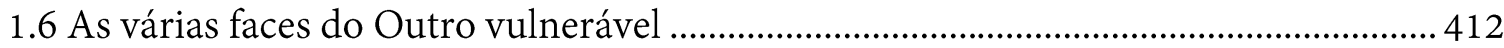

1.7 O direito de prioridade do Outro........................................................................................... 414

CONSIDERAÇÕES IN-FINITAS _ 417

BIBLIOGRAFIA _ 421 


\section{INTRODUÇÃO}

Há sempre que introduzir. Toda obra com efeito começa com uma palavra de acolhimento. Introdução do leitor. Extradição do autor. É preciso abrir as portas da própria casa. Mundo privado, ainda meu, recôndito da minha intimidade, dá-se àquele que chega de fora, para quem o meu mundo é ainda um mundo desconhecido. Haverá escritura sem pudor? Nesta sua abertura, o que é privado se publiciza. Cumpre a função social de toda palavra: a de ser dada a alguém; de se fazer proposição. Intro-dução como modo, pois, de ir já recebendo, recebendo como que de partida. Doando-se. Talvez a ponto mesmo de ser possível algo como o "milagre" da poesia: "um livro com meu nome sem uma palavra minha"1. Introdução à guisa de des-apropri-ação.

Escreve-se uma introdução sempre ao final: quando tudo está acabado. Momento em que o próprio autor já está de fora do que foi "produzido": quando o que resta, depois de que tudo já está entregue, é ser de algum modo o seu primeiro crítico. Porta de entrada do texto, trata-se inevitavelmente de um "Dito" posterior. No seu "lugar" à parte, destinase não só a explicitar a estrutura e o movimento do trabalho como igualmente a adiantar em alguma medida o conteúdo que se encontrará mais à frente. Precisamente por isso já não se junta ao corpo da obra como obra de conhecimento, mas como manifestação de reconhecimento. Introdução como saudação. Como gesto de boas-vindas. Primeiro desdizer do texto, numa tentativa de redizê-lo da forma mais acessível possível, sem cerimonial, na sua preocupação com aquele que se depara diante de algo novo ${ }^{2}$.

O que esta tese tem, pois, a Dizer?

Antes de tudo, que não se trata de um exercício de mera exegese do pensamento de Emmanuel Levinas. Sem desrespeitá-lo, enfrenta o desafio de situá-lo num outro contexto, que é o da filosofia do direito, a fim de a partir dele pensar questões jurídicas em sua relação com questões humanas. A filosofia levinasiana é uma espécie de recrutamento. Sua linguagem própria (carregada de il faut, il faut, il faut...) dá prova da sua preocupação com a transformação da realidade. É preciso, pois, dar a conhecer aos juristas tal pensamento difícil, confiando em que possa ao mesmo tempo ter alguma utilidade prática. Isto exige

\footnotetext{
${ }^{1}$ PRADO, Adélia. Pontuação. In: Poesia reunida. 3. ed. Rio de Janeiro: Record, 2016, p. 464.

2 LEVINAS, Emmanuel. Totalidade e Infinito: ensaio sobre a exterioridade. Tradução de José Pinto Ribeiro. 3. ed. Lisboa: Edições 70, 2011, p. 16; LEVINAS, Emmanuel. Totalité et Infini: essai sur l'extériorité. Paris: Kluwer academic, 1991, p. 16.
} 
que se tenha consciente o papel da filosofia para o direito ou da própria filosofia do direito, que é precisamente o de colocar questões...

Onde, então, a filosofia do direito começa? Talvez ela comece colocando o próprio direito, o meu direito, em questão. Mais profunda de todas as questões do direito é a relativa a "saber" (mas se trata, afinal, de saber?): "Tenho direito a ser?" Esta pergunta, fundamental se se quer colocar o próprio direito em questão, é expressamente formulada por Emmanuel Levinas: "O desabrochar do humano no ser, a abertura no ser (...), a crise do ser, o outramente que ser, são marcados com efeito pelo fato de que o mais natural se torna o mais problemático. Será que tenho direito a ser? Será que no mundo eu não ocupo o lugar de alguém?"3

Como, porém, o filósofo do direito, ou o jurista, ou qualquer pessoa, chega a levantar uma tal questão primordial? Dizer que a filosofia do direito começa com uma tal questão não diz ainda de que modo ela se levanta, de que modo ela passa a atormentar a consciência, de que modo ela se eleva à condição de um problema filosófico: "Como o homem, na atitude inocente, mergulhado no mundo, o homem, esse 'dogmático nato', torna-se bruscamente consciente de sua inocência?"4

Não há filosofia geral nem filosofia do direito sem relação social. Em face do Homem, "dogmático nato", encontra-se um Outro homem, "zetético nato". É Outrem quem me coloca em questão. Não propriamente porque pensa, porque especula, porque é uma espécie de neurótico filosofante, mas porque é rosto. Rosto que abala a pretensão de todos os meus poderes, não confrontando o meu direito, mas requerendo dele uma justificação. A filosofia do direito, que pressupõe uma relação inter-humana, visage diante de visage, é uma filosofia da justiça. $\mathrm{O}$ meu direito se justifica em face do direito do Outro.

Da filosofia do direito não se pode dizer, portanto, que se cuida de mera perfumaria jurídica. Buscando o sentido do meu direito, do direito, dos direitos humanos, seu mister consiste em retirá-los do arbitrário, apartá-los da cerca de rosas que comprimem o mau cheiro que os assola enquanto não efetuam uma conversão. A filosofia do direito, que começa a modo de consciência invadida, má-consciência, consciência moral, está comprometida com uma nova orientação jurídica que é a do próprio direito orientado para o humano.

\footnotetext{
${ }^{3}$ LEVINAS, Emmanuel. Ética e Infinito: diálogos com Philippe Nemo. Tradução de João Gama e revisão de Artur Morão. Lisboa: Edições 70, 2000, p. 115; LEVINAS, Emmanuel. Ethique et Infini. Paris: Fayard/France Culture, 1982, p. 120.

${ }^{4}$ LEVINAS, Emmanuel. La théorie de l'intuition dans la phénoménologie de Husserl. Paris: Vrin, 1989, p. 222.
} 
É num quadro histórico de desarticulação do fenômeno jurídico, mas também de uma procura renovada pelo seu sentido, que este trabalho se propõe a re-pensar o direito outramente. A tese que defende é a de um direito enquanto resposta, e a da sua positividade enquanto responsabilidade - responsabilidade em face de um rosto, o rosto do Outro, que o interpela.

A tese está organizada em quatro partes: na primeira, busca explicitar a formação do direito na modernidade enquanto um direito pautado no Eu e os resultados desastrosos daí provenientes; na segunda, procura descrever o momento de crise do direito na pósmodernidade como ocasião propícia a uma reformulação do seu sentido, invocando o pensamento de Emmanuel Levinas como um referencial que permite compreender o jurídico à luz do Outro; na terceira, propõe-se a examinar temas atuais, como o dos "direitos humanos", o do "reconhecimento", o da "igualdade e diferença" e o da "dignidade da pessoa humana", a partir da ótica levinasiana; na quarta, debruça-se sobre a realidade jurídica brasileira contemporânea para nela encontrar a manifestação concreta das várias faces do Outro.

Deliberadamente adotando a perspectiva de uma filosofia que assume a si própria como uma "filosofia dos talvezes", jamais recusando o seu caráter problemático, na própria impossibilidade de dizer a alteridade, não se há de rejeitar nesta tese um certo caráter de hipótese. Hipótese, no mínimo, extravagante... por colocar no começo, no começo do começo, simplesmente um rosto humano... Hipótese, em todo caso, que é preciso defender, numa espécie de aventura prometedora daquilo que Emmanuel Levinas chamaria de um "belo risco a se correr". Esta tese, hipó-tese, agora ex-posta, ao menos não se furta a uma tal responsabilidade de pensar o direito a serviço da alteridade humana. 


\section{CONSIDERAÇÕES IN-FINITAS}

Assim como a introdução se abre para o leitor como o primeiro desdizer do texto que se lê - um desdizer que, à medida que diz novamente e de outro modo, é um dizer necessário -, Levinas não concebe a conclusão (a parte final de um texto) senão como uma outra tentativa, uma tentativa final, quase desesperada, de dizer novamente o que já foi dito. É preciso, ainda e uma última vez, mesmo que de maneira sumária, retomar a palavra - desfazer os pontos.

A primeira parte desta tese intentou descrever o processo de constituição da modernidade, procurando descortinar a inserção do direito no seu interior. O que se sustentou, aí, foi a construção de um direito a serviço do $\mathrm{Eu}$, de um projeto de "emancipação" que tinha como referência um sujeito egoísta tendente a negar a alteridade humana: o direito que emerge é um direito que despersonaliza o Outro, que o reduz a um papel social e que impede que sua diferença absoluta desponte - a pessoa se transforma na figura abstrata de um sujeito jurídico. Não há, porém, como compreender o direito moderno sem considerar alguns dos seus principais referenciais teóricos. Daí a preocupação em examinar a filosofia kantiana do direito e a teoria jurídica de Hans Kelsen. Em Immanuel Kant, encontra-se a fundamentação mais acabada da ordem jurídica moderna, centrada na ideia de liberdade, enquanto que, no jurista austríaco, se pode localizar a principal contribuição, também na modernidade, para a construção de uma ciência jurídica pretensamente autônoma. Sob tais bases é que o direito moderno alcançará, no final do século XX, uma configuração desligada de qualquer referência à justiça e à ética, deparando-se com a catástrofe do Holocausto.

$\mathrm{O}$ foco da tese se altera na segunda parte: passa da modernidade à pósmodernidade, a qual se procura delinear, atentando-se, ainda, às suas repercussões no plano jurídico. Se a modernidade havia sido descrita como expressão de um Eu egoísta, a pósmodernidade aparece, aqui, como instante extraordinário da história da humanidade em que um Outro desabrocha e reclama por responsabilidades. Cada vez mais presente em nossas vidas, apesar de todas invectivas no sentido de afastá-lo do convívio social, Outrem, em seu rosto, convoca o direito a se constituir de uma forma inédita, adquirindo um novo sentido. No contexto da pós-modernidade, o problema da alteridade adquire de vez centralidade no bojo das preocupações filosóficas. É na filosofia de Emmanuel Levinas, no entanto, que uma tal atenção é conduzida à sua radicalidade, ao extremo de permitir uma nova compreensão do direito e da pessoa humana. 
A terceira parte da tese manifesta a intenção de materializar a filosofia levinasiana no contexto de algumas questões que têm ocupado o debate teórico contemporâneo. Os direitos humanos, relidos à luz do pensamento de Emmanuel Levinas, são traduzidos, antes de mais, como direitos do Outro homem. Analisada sob a ótica da ética da responsabilidade, a ideia de reconhecimento é, neste espaço, pensada como acolhimento e saudação. "Igualdade e diferença", esta dupla categórica que tem suscitado intensas discussões no âmbito da filosofia política e da filosofia do direito, é objeto de uma leitura singular que busca enxergar num polo e noutro expressões intermitentes da ideia de justiça. Finalmente, a dignidade da pessoa humana é reinterpretada a partir do cabedal filosófico apresentado, capaz de nela distinguir ao menos três expressões: dignidade do Outro; dignidade do eu; dignidade do cidadão. Simultaneamente talhada como princípio e anarquia, a dignidade da pessoa humana é fonte irradiadora de sentido de uma ordem jurídica do desejo.

Em sua quarta e última parte, a tese dá um "salto para baixo" em direção à realidade jurídica brasileira, a fim de nela deixar ecoar a filosofia levinasiana: de um lado, demonstra como é falsa a crença de que o Brasil se consubstanciaria num país pacífico e acolhedor das diferenças; de outro, porém, não deixa de reconhecer que o estabelecimento de novas legislações têm apontado para uma ideia de direito talvez próxima daquela que se procurou defender ao longo do trabalho, isto é, a de um direito como resposta, a sua positividade como manifestação de uma responsabilidade por um rosto que, sob as mais variadas faces, o interpela.

Levar a ideia de responsabilidade a sério implica considerar a justiça como uma tarefa infinita a cargo do direito. Porque não se confunde com uma mera necessidade, o desejo de justiça não se satisfaz; de algum modo, quanto mais dela me aproximo mais minha distância relativamente a ela se alarga. Pensar uma tal coisa pode ter qualquer coisa de decepcionante, pois retira de mim a esperança de uma vida finalmente em repouso, mas ao menos me revela a inquietude nunca apaziguada que a move no interior de um tempo que não corre em direção ao nada da morte, mas que se verte do Mesmo para o Outro. Não como rio, mas como lágrima. Condição da justiça é a de um direito que, se humanizando, chora em face de um rosto humano... 
Como uma carta de Levinas a Blanchot ${ }^{1666}$, esta tese termina (termina?) também sem conclusão, porque, ciente de que tudo teria cabido numa única página, a consciência remanesce inquieta de que muito ainda haveria a ser Dito, ou mesmo Desdito, de que muito ainda resta por Dizer. De modo que estas considerações permanecem in-finitas; não constituem um ponto final

1666 "Eis uma tão longa carta e que é, sem dúvida, sem conclusão. Sou eu o único neste estado sem conclusão em que sei o que tenho de fazer, mas em que ignoro o que devo pensar em fim de contas?" (LEVINAS, Emmanuel. Être juif: suivi d'une lettre à Maurice Blanchot. Paris: Rivages, 2015, p. 77). 


\section{BIBLIOGRAFIA}

ABENSOUR, Miguel. El mal elemental. In: LEVINAS, Emmanuel. Algunas reflexiones sobre la filosofia del hitlerismo. Tradução de Ricardo Ibarlucía e Beatriz Horrac. Buenos Aires: Fondo de cultura económica, 2006.

. Emmanuel Levinas, l'intrigue de l'humain: entre métapolitique et politique. Paris: Hermann: 2012.

Le contre-Hobbes d'Emmanuel Levinas. In: HALPÉRIN, Jean; HANSSON, Nelly (Org.) Difficile justice: dans la trace d'Emmanuel Levinas - Actes du XXXVIe colloque des intellectuels juifs de langue française. Paris: Albin Michel, 1998.

- Le mal élémental. Disponível em: <http://www.antirev.org/textes/Abensour97a/>. Acesso em: 9. mar. 2016.

L'extravagante hypothèse. In: Rue Descartes: Emmanuel Levinas. Paris: PUF, 2006

ADEODATO, João Maurício. Ética e retórica: para uma teoria da dogmática jurídica. 5. ed. São Paulo: Saraiva, 2012.

ADORNO, Sérgio. A violência na sociedade brasileira: um painel inconcluso em uma democracia não consolidadea, Revista Sociedade e Estado, v. 10, n. 2, p. 299-342, jul.dez. 1995.

Violência e racismo: discriminação no acesso à justiça penal. In: SCHWARCZ, Lilia Moritz; QUEIROZ, Renato da Silva (Orgs.). Raça e diversidade. São Paulo: EdUSP, 1996.

ADORNO, Sérgio; LAMIN, Cristiane. Medo, violência e insegurança. In: LIMA, Renato Sérgio de; PAULA, Liana de (Orgs.). Segurança pública e violência: o Estado está cumprindo seu papel? São Paulo: Contexto, 2008. 
ADORNO, Theodor W. Conceito de Iluminismo (em parceria com Horkheimer). Coleção “Os Pensadores”. São Paulo: Nova Cultural, 1996.

ADORNO, Theodor W.; HORKHEIMER, Max. Dialética do esclarecimento: fragmentos filosóficos. Tradução de Guido Antonio de Almeida. Rio de Janeiro: Jorge Zahar, 2006.

AGAMBEN, Giorgio. K. In: Nudez: Belo Horizonte: Autêntica, 2014

O que é o contemporâneo? e outros ensaios. Tradução de Vinícius Nicastro Honesko. Chapecó: Argos, 2009.

AGOSTINHO, Santo. Confissões. Tradução de Maria Luiza Jardim Amarante. São Paulo: Paulus, 1984.

AKERMAN, Marco; BOUSQUAT, Aylene. Mapas de risco de violência, São Paulo Perspec., São Paulo, v. 13, n. 4, p. 112-120, dez. 1999. Disponível em:

$<$ http://www.scielo.br/scielo.php?script=sci_arttext\&pid=S010288391999000400012\&lng $=$ en\&nrm=iso>. Acesso em: 10 set. 2017.

ALLOA, Emmanuel. Par-delà la reconnaissance. L'attention come paradigme pour une éthique asymétrique, Alter, Revue de Phénoménologie, Paris, n. 18 [L'attention], p. 125$141,2010$.

ARENDT, Hannah. A condição humana. Tradução de Roberto Raposo. 10. ed. Rio de Janeiro: Forense Universitária, 2007.

Da revolução. Tradução de Fernando Dídimo Vieira. São Paulo: Ática; Brasília: UNB, 1998.

Entre o passado e o futuro. Tradução de Mauro W. Barbosa. 7. ed. São Paulo: Perspectiva, 2013. 
. Origens do totalitarismo. Tradução de Roberto Raposo. São Paulo: Companhia das Letras, 1989.

Responsabilidade e julgamento. Tradução de Rosaura Eichenberg. São Paulo: Companhia das Letras, 2004.

ARISTÓTELES. A política. Tradução de Nestor Silveira Chaves. 2. ed. rev. Bauru: EDIPRO, 2009.

ARISTÓTELES. Ética a Nicômaco. Tradução de António de Castro Caeiro. São Paulo: Atlas, 2009.

AUDI, Paul. Présentation. In: LYOTARD, Jean-François. Logique de Levinas. Lagrasse: Verdier, 2015.

AUSTIN, Lisa M. A postmodern defence of universal liberal legal norms, Canadian journal of law and jurisprudence, v. XXIII, n. 1, p. 5-31, january 2010.

BAILHACHE, Gérard. Le sujet chez Emmanuel Levinas: fragilité et subjectivité. Paris: PUF, 1994.

BALBONTIN-GALLO, Cristóbal. Constitution de l'identié individuelle et lutte pour la reconnaissance: plaidoyer pour une critique de Hegel. S.L. S. D. P. 8. Disponível em: <http://www.academia.edu/9845107/Constitution_de_lidentit\%C3\%A9_individuelle_et_re connaissance>. Acesso em: 31 mai. 2017.

Hegel/Levinas et le problème de la reconnaissance. S.L. S. D. Disponível em:

<http://www.academia.edu/11640676/Hegel_Levinas_et_le_probl\%C3\%A8me_de_la_rec

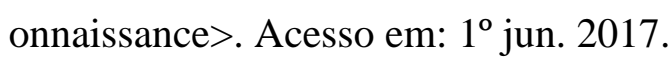

BALSEMÃO, Edmundo. A realidade do Tempo segundo Levinas: considerações gerais e proposições introdutórias sobre o tema da temporalidade em E. Levinas, Revista Portuguesa de Filosofia, Braga, t. 47, fasc. 1, p. 119-177, jan.-mar., 1991. 
BANON, David. Exégèse biblique et philosophie. In: GREISCH, Jean; ROLLAND, Jacques. (Dirs.) Emmanuel Levinas: l'éthique comme philosophie première (actes du colloque de Cerisy-la-Salle, 23 août- 2 septembre 1986). Paris: Cerf, 1993.

BARRACA, Javier. La alternativa de E. Levinas a la versión moderna de la universalidad de los derechos humanos, Persona y derecho: revista de fundamentación de las instituciones jurídicas y de derechos humanos, Navarra, n. 56, p. 393-408, 2007.

BAUDELAIRE, Charles. Sobre a modernidade. Tradução de Teixeira Coelho. Rio de Janeiro: Paz e Terra, 1996.

BAUMAN, Zygmunt. A vida fragmentada: ensaios sobre a moral pós-moderna. Tradução de Miguel Serras Pereira. Lisboa: Relógio D’Água, 2007.

Bauman sobre Bauman: diálogos com Keith Tester. Tradução de Carlos Alberto Medeiros. Rio de Janeiro: Zahar, 2011.

Ética pós-moderna. Tradução de João Rezende Costa. São Paulo: Paulus, 1997.

Modernidade e ambivalência. Tradução de Marcus Penchel. Rio de Janeiro: Jorge Zahar, 1999.

Modernidade e holocausto. Tradução de Marcus Penchel. Rio de Janeiro: Jorge Zahar, 1998.

Modernidade líquida. Tradução de Plínio Dentzien. Rio de Janeiro: Zahar, 2001.

BECKERT, Cristina. Reconhecimento assimétrico do outro ao terceiro. In: MARCOS, Maria Lúcia; COUTINHO, Maria João; BARCELOS, Paulo. (Orgs.) Emmanuel Levinas: entre reconhecimento e hospitalidade. Lisboa: Edições 70, 2011. 
BENSUSSAN, Gérard. Ética e experiência: a política em Levinas. Tradução de Ozanan Vicente Carrara. Passo Fundo: IFIBE, 2009.

BERNARDO, Fernanda. A assinatura ético-metafísica da experiência do cativeiro de Emmanuel Levinas: uma nova orientação para a filosofia - uma outra incondição para o humano, Revista Filosófica de Coimbra, Coimbra, n. 41, p. 107-174, 2012.

- Da responsabilidade ética à ético-político-jurídica: a incondição da responsabilidade ética enquanto incondição da subjectividade do sujeito segundo Emmanuel Levinas, Revista filosófica de Coimbra, Coimbra, n. 16, p. 269-340, 1999.

- Da responsabilidade ética à ético-político-jurídica: a incondição da responsabilidade ética enqua nto incondição da subjectividade do sujeito segundo Emmanuel Levinas (II), Revista filosófica de Coimbra, Coimbra, n. 17, p. 63-95, 2000.

BERNASCONI, Robert. Levinas, Hegel: la possibilite du pardon e de la réconciliation. Tradução para o francês de Guy Petitdemange. In: CHALIER, Catherine; ABENSOUR, Miguel (Orgs.). L'Herne: Emmanuel Levinas, Paris, 2006.

BIERHANZL, Jan. Signifiance éthique et corporéité dans Autrement qu'être ou au-delà de l'essence, Studia phaenomenologica: Romanian Journal for Phenomenology, Bucharest, v. 12: Possibilities of embodiment, p. 85-107, 2012.

BLANCHOT, Maurice. A comunidade inconfessável. Tradução de Eclair Antonio Almeida Filho. Brasília: UnB; Bauru: Lumme, 2013.

La communauté inavouable. Paris: Éditions de Minuit. 1983.

Paix, paix au lointain et au proche. In: HALPÉRIN, Jean; HANSSON, Nelly (Org.) Difficile justice: dans la trace d'Emmanuel Levinas - Actes du XXXVIe colloque des intellectuels juifs de langue française. Paris: Albin Michel, 1998.

BITTAR, Eduardo C. B. A justiça em Aristóteles. 3. ed. rev. e ampl. Rio de Janeiro: Forense Universitária, 2005. 
A teoria aristotélica da justiça. Revista da Faculdade de Direito, Universidade de São Paulo, São Paulo, SP, v. 92, p. 53-73, 1997.

Curso de ética jurídica: ética geral e profissional. 9. ed. São Paulo: Saraiva, 2012.

Democracia, justiça e direitos humanos: estudos de teoria crítica e filosofia do direito. São Paulo: Saraiva, 2011.

Ética, educação, cidadania e direitos humanos: estudos filosóficos entre cosmopolitismo e responsabilidade social. Barueri: Manole, 2004.

Ética, técnica e direitos humanos, Revista Brasileira de Estudos Políticos, Belo Horizonte, n. 103, p. 139-182, jul./dez.2011.

Filosofia crítica e filosofia do direito: por uma filosofia social do direito, Revista Cult. Disponível em: <https://revistacult.uol.com.br/home/filosofia-critica-efilosofia-do-direito-por-uma-filosofia-social-do-direito/> Acessado em: 13.9.2017.

Justiça e emancipação: reflexões jusfilosóficas a partir do pensamento de Jürgen Habermas. 2011. 968f. Tese (Prof. Titular) - Faculdade de Direito, Universidade de São Paulo, São Paulo, 2011.

. Hermenêutica e Constituição: a dignidade da pessoa humana como legado à pós-modernidade. In: FERRAZ, Anna Candida da Cunha; BITTAR, Eduardo C. B. (Orgs.) Direitos humanos fundamentais: positivação e concretização. Osasco: EDIFIEO, 2006.

Metodologia da pesquisa jurídica: teoria e prática da monografia para os cursos de direito. 11. ed. São Paulo: Saraiva, 2013.

. O Decreto $n^{\circ} 8.243 / 2014$ e os desafios da consolidação democrática brasileira, Revista de Informação Legislativa, Brasília, n. 203, ano 51, p. 7-38, jul./set. 2014. 
O direito na pós-modernidade e reflexões frankfurtianas. 2. ed. rev., atual. e ampl. Rio de Janeiro: Forense Universitária, 2009.

Os direitos humanos e a sensibilidade estética: educação em direitos humanos, resistência e transformação social. In: FERREIRA, Lúcia de Fátima Guerra; ZENAIDE, Maria de Nazaré Tavares; PEQUENO, Marconi (Orgs.). Direitos humanos na educação superior: subsídios para a educação em direitos humanos na filosofia. João Pessoa: UFPB, 2010 .

Reconhecimento e direito à diferença: teoria crítica, diversidade e a cultura dos direitos humanos, Revista da Faculdade de Direito da Universidade de São Paulo, São Paulo, v. 104, p. 551-565, jan./dez. 2009.

BITTAR, Eduardo C. B.; ALMEIDA, Guilherme de Assis. Curso de Filosofia do Direito. 10. ed. rev. e atual. São Paulo: Atlas, 2012.

BOBBIO, Norberto. A era dos direitos. Tradução de Nelson Coutinho. Rio de Janeiro: Elsevier, 2004.

Direito e Estado no pensamento de Emanuel Kant (sic). Tradução de Alfredo Fait. Brasília: Universidade de Brasília, 1984.

O positivismo jurídico: lições de filosofia do direito. Tradução de Márcio Pugliesi, Edson Bini e Carlos E. Rodrigues. São Paulo: Ícone, 2006.

BOJANIC, Petar. "Esse paladar de violência": sobre violência contra violência. In: MARCOS, Maria Lúcia; COUTINHO, Maria João; BARCELOS, Paulo. (Orgs.) Emmanuel Levinas: entre reconhecimento e hospitalidade. Lisboa: Edições 70, 2011.

BRAGA, Eneida Cardoso. A escuta do outro em Emmanuel Levinas e Sigmund Freud. In: SOUZA, Ricardo Timm de; FARIAS, André Brayner de; FABRI, Marcelo Fabri (Orgs.). Alteridade e ética: obra comemorativa dos 100 anos de nascimento de Emmanuel Levinas. Porto Alegre: EDIPUCRS, 2008. 
BRASIL. Instituto de Pesquisa Econômica Aplicada. Reincidência criminal no Brasil: relatório de pesquisa. Rio de Janeiro, 2015. Disponível em: <http://www.cnj.jus.br/files/conteudo/destaques/arquivo/2015/07/572bba385357003379ffe b4c9aa1f0d9.pdf> Acesso em: 8 set. 2017.

BRITO, Alejandro Guzmán. Historia de la denominación del derecho-facultad como "subjetivo", Revista de estúdios histórico-jurídicos, Valparaíso, n. XXV, p. 407-443, 2003. . Los orígenes de la noción de sujeto de derecho. Revista de estudios históricojurídicos, n. 24, 151-247, 2002.

BRUMLIK, Micha. Una lectura de "Quelques réflexions sur la philosophie de l'hitlerisme". Tradução de Andrés Miguel Osswald. In: DREIZIK, Pablo (Comp.). Levinas y lo político. Buenos Aires: Prometeo Libros, 2014.

BUBER, Martin. Eu e Tu. Tradução de Newton Aquiles Von Zuben. São Paulo: Centauro, 2015.

CABRIADA, Gustavo Perez; WARAT, Luis Alberto. Os quadrinhos puros do direito. Buenos Aires: ALMED, s.d.

CAHNÉ, Pierre-Alain. Un autre Descartes: le philosophe et son langage. Paris: Vrin, 1980.

CALDEIRA, Teresa Pires do Rio. Cidade de muros: crime, segregação e cidadania em São Paulo. 2. ed. São Paulo: Ed. 34/EdUSP, 2000.

Direitos humanos ou "privilégios de bandidos"? Desventuras da democratização brasileira, Novos Estudos CEBRAP, São Paulo, n. 30, p. 162-174, jul. 1991.

CALIN, Rodolphe. Lexique lévinassien, Cités, Paris, n. 25, p. 139-148, 2006/1. 
CALIN, Rodolphe; SEBBAH, François-David. Le vocabulaire de Levinas. Paris: Ellipses, 2002.

CARRARA, Ozanan Vicente. Ética e Ontologia em Emmanuel Levinas. Revista Estudos Filosóficos, São João del-Rei, MG, n. 8, p. 33-50, 2012/1.

Levinas: do sujeito ético ao sujeito político - elementos para pensar a política outramente. Aparecida: Ideias e Letras, 2010.

CARVALHO, Felipe Rodolfo de. O processo de homogeneização jurídica na modernidade. 2011, 185 f. Monografia (Graduação em Direito) - Faculdade de Direito, Universidade Federal de Mato Grosso, Cuiabá.

Reconstruindo o direito subjetivo: uma proposta a partir de Jürgen Habermas. In: PIRES, Natacha F. N.; SIMÕES, Alexandre G. (Orgs.) Ensaios sobre a história e a teoria do direito social: construção do saber jurídico \& função política do direito. São Paulo: Letras Jurídicas, 2012.

CARVAlHO, José Murilo de. Cidadania no Brasil: o longo caminho. 10. ed. Rio de Janeiro: Civilização Brasileira, 2008.

CASALONE, Carlo. Levinas: ética e filosofia no pensamento pós-moderno, Tradução de Nilo Ribeiro Júnior e Marcelo Perine, Revista Síntese Nova Fase, Belo Horizonte, v. 20, n. 62, p. 341-354, 1993.

CHALIER, Catherine. Éthique et politique. In: HALPÉRIN, Jean; HANSSON, Nelly (Org.) Difficile justice: dans la trace d'Emmanuel Levinas - Actes du XXXVIe colloque des intellectuels juifs de langue française. Paris: Albin Michel, 1998.

La fraternité, un espoir en clair-obscur. Paris: Buchet; Chastel, 2003.

La persévérance du mal. Paris: CERF, 1987.

Levinas: A utopia do humano. Tradução de António Hall. Lisboa: Piaget, 1996. 
Pour une morale au-delà du savoir: Kant et Levinas. Paris: Albin Michel, 1998.

CIARAMELLI, Fabio. L'appel infini à l'interprétation: remarques sur Levinas et l'art, Revue Philosophique de Louvain, Louvain, quatrième série, t. 92, n. 1, p. 32-52, 1994.

CINTRA, Benedito Eliseu Leite. Ternura. In: SUSIN, Luiz Carlos et. al. (Orgs.). Éticas em diálogo: Levinas e o pensamento contemporâneo - questões e interfaces. Porto Alegre: EDIPUCRS, 2003.

CITTADINO, Gisele. Pluralismo, direito e justiça distributiva: elementos da filosofia constitucional contemporânea. 4. ed. Rio de Janeiro: Lumen Juris, 2009.

COELHO JR., Nelson; FIGUEIREDO, Luís Claudio. Figuras da intersubjetividade na constituição subjetiva: dimensões da alteridade. In: Dimensões da intersubjetividade. COELHO JR., Nelson; SALEM, Pedro; KLAUTAU, Perla. (Org.) São Paulo: FAPESP/Escuta, 2012.

COING, Helmut. Derecho privado europeo: derecho común más antiguo (1500-1800). Tradução de Antonio Perez Martín. Madrid: Fundação Cultural del Notariado, 1996, t. 1.

Signification de la notion de droit subjectif, Archives de philosophie du droit, n. 9: le droit subjectif en question, Paris, Sirey, p. 1-15, 1964.

COMPARATO, Fábio Konder. A afirmação histórica dos direitos humanos. 7. ed. rev. e atual. São Paulo: Saraiva, 2010.

Ética: direito, moral e religião no mundo moderno. São Paulo: Companhia das Letras, 2006.

CORREAS, Óscar. El otro Kelsen. In: CORREAS, Óscar (Comp.). El otro Kelsen. México: Universidad Nacional Autónoma de México, 1989. 
COSTA, José Andé. Direitos humanos como reconhecimento da alteridade no pensamento de E. Levinas. In: SOUZA, Ricardo Timm de; FARIAS, André Brayner de; FABRI, Marcelo Fabri (Orgs.). Alteridade e ética: obra comemorativa dos 100 anos de nascimento de Emmanuel Levinas. Porto Alegre: EDIPUCRS, 2008.

. Emmanuel Levinas: direitos humanos e reconhecimento da alteridade. In: CARBONARI, Paulo César (Org.). Sentido filosófico dos direitos humanos: leituras do pensamento contemporâneo. Passo Fundo: IFIBE, 2006.

. Ética e política em Levinas: alteridade, responsabilidade e justiça. Passo Fundo: IFIBE, 2013.

COSTA, Sergio. Unidos e iguais? Anti-racismo e solidariedade no Brasil contemporâneo, Pensamiento ibero-americano, n. 1, p. 231-250, 2007.

CRITCHLEY, Simon. Introduction; PUTNAM, Hilary. Levinas and Judaism. In: CRITCHLEY, Simon; BERNASCONI, Robert (Orgs.). The Cambridge Companion to Levinas. Cambridge: Cambridge University Press, 2004.

CRITCHLEY, Simon. Introdução a Emmanuel Levinas. In: HADDOCK-LOBO, Rafael. Da existência ao infinito: ensaios sobre Emmanuel Levinas. Rio de Janeiro: PUC-Rio; São Paulo: Loyola, 2006. . Religião, para Levinas, é ética, Revista do Instituto Humanistas Unisinos, n. 277: Levinas e a majestade do Outro, a. VIII, 2008, disponível em: $<$ http://www.ihuonline.unisinos.br/index.php?option=com_content\&view=article\&id=223 $\underline{1 \& \text { secao }=277}>$. Acesso em: $31 \mathrm{dez} .2016$.

The ethics of deconstruction: Derrida and Levinas. 2. ed. Edinburgh: Edinburgh University Press, 1999.

CROWE, Jonathan. Self and other in ethics and law: a comment on Manderson, Australian Journal of Legal Philosophy, v. 33, p. 145-151, 2008. 
CRUZ, Álvaro Ricardo de Souza. O direito à diferença: as ações afirmativas como mecanismos de inclusão social de mulheres, negros, homossexuais e pessoas portadoras de deficiência. 3. ed. rev., ampl. e atual. Belo Horizonte: Arraes, 2009.

CUNHA, Paulo Ferreira da. Filosofia jurídica prática. Belo Horizonte: Fórum, 2009.

DAMATTA, Roberto. O que faz o brasil, Brasil? Rio de Janeiro: Rocco, 1986.

DAVIS, Colin. Levinas: an introduction. Cambridge: Politty Press, 2007.

DE CICCO, Cláudio. História do pensamento jurídico e da filosofia do direito. 7. ed. ref. São Paulo: Saraiva: 2013.

DERRIDA, Jacques. Adeus a Emmanuel Levinas. Tradução de Fábio Landa com a colaboração de Eva Landa. São Paulo: Perspectiva, 2008.

Anne Dufourmantelle convida Jacques Derrida a falar da hospitalidade.

Tradução de Antonio Romane. São Paulo: Escuta, 2003.

Força de lei. Tradução de Leyla Perrone-Moisés. 2. ed. São Paulo: Martins Fontes, 2010.

DESCARTES, René. Discurso do método. Tradução de J. Guinsburg e Bento Prado Jr. Coleção “Os pensadores”. São Paulo: Nova cultural, 1996.

Meditações metafísicas. Tradução de Maria Ermantina Galvão. São Paulo: Martins Fontes, 2005.

DIAMANTIDES, Marinos. Levinas and critical legal thought: imbróglio, opera buffa, divine comedy? In: DIAMANTIDES, Marinos (Ed.). Levinas, law, politics. Abingdon: Routledge-Cavendish, 2007, p. 179-215.

DI SANTE, Carmine. Responsabilidade: o eu - para - o - outro. Tradução de Ivo Storniolo. São Paulo: Paulus, 2005. 
DOSTOIÉVSKI, Feódor Mikhailovitch. O jogador. Tradução de Roberto Gomes. Porto Alegre: L\&PM, 2007.

Os irmãos Karamázovi. Tradução de Natália Nunes e Oscar Mendes. 2. ed. Abril Cultural: 1973.

DOUZINAS, Costas. O fim dos direitos humanos. Tradução de Luzia Araújo. São Leopoldo: Unisinos, 2009.

DOUZINAS, Costas; WARRINGTON, Ronnie. The face of justice: a jurisprudence of alterity, Social Legal Studies, London, v. 3, n. 3, p. 405-425, 1994.

DREIZIK, Pablo. La posibilidad del liberalismo em Levinas. "Quelques réflexions sur la philosophie de l'hitlérisme" entre dos lecturas de Husserl. In: DREIZIK, Pablo (Comp.). Levinas y lo político. Buenos Aires: Prometeo Libros, 2014.

DUPUY, Bernard. Exégèse et philosophie dans l'oeuvre d'Emmanuel Levinas. In: GREISCH, Jean; ROLLAND, Jacques. (Dirs.) Emmanuel Levinas: l'éthique comme philosophie première (actes du colloque de Cerisy-la-Salle, 23 août- 2 septembre 1986). Paris: Cerf, 1993.

DURKHEIM, Émile. Da divisão do trabalho social. Tradução de Eduardo Brandão. São Paulo, Martins Fontes, 1999.

DUSSEL, Enrique. 1492 - O encobrimento do outro: a origem do mito da modernidade. Tradução de Jaime A. Clasen. Petrópolis: Vozes, 1993.

ECO, Umberto. Como se faz uma tese. Tradução de Gilson Cesar Cardoso de Souza. 18. ed. São Paulo: Perspectiva, 2003.

ELLA, Steeve. Emmanuel Levinas: des droits de l'homme à l'homme. Paris: L'Harmattan, 2009. 
ENDO, Paulo Cesar. A violência no coração da cidade: um estudo psicanalítico sobre as violências na cidade de São Paulo. São Paulo: Escuta/FAPESP, 2005.

ENGISH, Karl. Introdução ao pensamento jurídico. Tradução de João Baptista Machado. Lisboa: Calouste Gulbenkian, 2001.

EPSTEIN, Daniel. La Shoah comme traumatisme éthique dans l'oeuvre d'E. Levinas. In: HALPÉRIN, Jean; HANSSON, Nelly (Org.) Difficile justice: dans la trace d'Emmanuel Levinas - Actes du XXXVIe colloque des intellectuels juifs de langue française. Paris: Albin Michel, 1998.

FABRI, Marcelo. Desencantando a ontologia: subjetividade e sentido ético em Levinas. Porto Alegre: EDIPUCRS, 1997.

FAESSLER, Marc. Humilité du signe et kénose de Dieu. In: GREISCH, Jean; ROLLAND, Jacques. (Dirs.) Emmanuel Levinas: l'éthique comme philosophie première (actes du colloque de Cerisy-la-Salle, 23 août- 2 septembre 1986). Paris: Cerf, 1993.

FARIA, Maria do Carmo B. de. Direito e Ética: Aristóteles, Hobbes, Kant. São Paulo: Paulus, 2007.

FERNANDES, Florestan. O negro no mundo dos brancos. 2. ed. rev. São Paulo: Global, 2007.

FERRAZ JR., Tercio Sampaio. A dialética do senhor escravo e o preço da desigualdade. Palestra, Seminário da Feiticeira, Ilha Bela, 27 nov. 2016. Disponível em: $<$ http://genjuridico.com.br/2016/11/27/seminario-da-feiticeira-01-dialetica-do-senhorescravo-e-o-preco-da-desigualdade/>. Acesso em: 6 jun. 2017.

A trivialização dos direitos humanos, Novos Estudos CEBRAP, São Paulo, n. 28, out. 1990, p. 99-115. 
.Constituições culturais: a razão e o afeto na política. In: FORBES, Jorge; REALE JR., Miguel; FERRAZ JR., Tercio Sampaio (Coords.). A invenção do futuro: um debate sobre a pós-modernidade e a hipermodernidade. Barueri: Manole, 2005.

Direito subjetivo: formação do conceito e limites operacionais. In: BAPTISTA, Luiz Olavo; FONSECA, José Roberto Franco da. (Coords.) O direito internacional no terceiro milênio: estudos em homenagem ao Professor Vicente Marotta Rangel. São Paulo: LTR, 1998.

Estudos de filosofia do direito: reflexões sobre o poder, a liberdade, a justiça e o direito. 3. ed. São Paulo: Atlas, 2009.

Hans Kelsen, um divisor de águas 1881-1981, Sequiência: Estudos Jurídicos e Políticos, Florianópolis, v. 3, n. 4, p. 133-138, jan. 1982.

Introdução ao estudo do direito: técnica, decisão, dominação. 5. ed. rev. e ampl. São Paulo: Atlas, 2007.

. O direito, entre o futuro e o passado. São Paulo: Noeses, 2014.

O futuro do direito. Revista USP, São Paulo, SP, n. 74, p. 6-21, jun./ago. 2007.

FIGUEIREDO, Luís Claudio. O interesse de Levinas para a psicanálise: desinteresse do rosto. Cadernos de Subjetividade, São Paulo, v. 5, n. 1, p. 39-52, 1997.

FORBES, Jorge. Mundo mutante, século XXI: as identidades em crise. In: FORBES, Jorge; REALE JR., Miguel; FERRAZ JR., Tercio Sampaio (Coords.). A invenção do futuro: um debate sobre a pós-modernidade e a hipermodernidade. Barueri: Manole, 2005.

Apresentação de Gilles Lipovetzky e introdução aos debates. In: FORBES, Jorge; REALE JR., Miguel; FERRAZ JR., Tercio Sampaio (Coords.). A invenção do futuro: um debate sobre a pós-modernidade e a hipermodernidade. Barueri: Manole, 2005. 
FORTE, Bruno. À escuta do outro: filosofia e revelação. Tradução de Mário José Zambiasi. 2. ed. São Paulo: Paulinas, 2010.

Um pelo outro: por uma ética da transcendência. Tradução de Silva Debetto C. Reis. São Paulo: Paulinas, 2006.

FOUTO, Ana Isabel Barceló Caldeira. Perspectivas históricas acerca do direito subjectivo. In: PIRES, Natacha F. N.; SIMÕES, Alexandre G. (Orgs.) Ensaios sobre a história e a teoria do direito social: construção do saber jurídico \& função política do direito. São Paulo: Letras Jurídicas, 2012.

FRASER, Nancy. Da redistribuição ao reconhecimento? Dilemas da justiça numa era "póssocialista", Tradução de Julio Assis Simões, Cadernos de campo, Revista dos alunos de pós-graduação em antropologia social da USP, São Paulo, n. 14-15, p. 231-239, 2006.

FREYRE. Casa-grande \& senzala: formação da família brasileira sob o regime da economia patriarcal, 51. ed. rev., 2016.

FROMM, Eric. A arte de amar. Tradução: Milton Amado. Belo Horizonte: Itatiaia, 1958.

GIDDENS, Anthony. As consequências da modernidade. Tradução de Raul Fiker. São Paulo: UNESP, 1991.

GOETHE, Johann Wolfgang von. Os sofrimentos do jovem Werther. Tradução de Oliver Tolle. São Paulo: Hedra, 2006.

GÓGOL, Nikolai. Le manteau. Tradução de León Goldschaman e Ernest Jaubert. S. 1.: Bibliothèque électronique du Québec, s. d., p. 6. Disponível em: < https://beq.ebooksgratuits.com/vents/Gogol-manteau.pdf >. Acesso em 17-9-2016.

GOMES, Dias. O santo inquérito. 28. ed. Rio de Janeiro: 2010. 
GOYARD-FABRE, Simone. L'idée d'ordre dans la théorie juridique de Kelsen, Cahiers de philosophie politique et juridique, n. 9: La philosophie du droit de Hans Kelsen, Caen, Centre de Publications de l'Université de Caen, 1986, p. 25-41, 1986.

Responsabilité morale et responsabilité juridique selon Kant, Archives de philosophie du droit, t. 22: la responsabilité, Paris, Sirey, p. 113-129, 1977.

- Sujet de droit et objet de droit: defense de l'humanisme, Cahiers de philosophie politique et juridique, n. 14: Sujet de droit et objet de droit - L'homme est-il le seul sujet de droit?, Caen, Presses Universitaires de Caen, p. 7-30, 1993.

GROCIO, Hugo. Del derecho de la guerra y de la paz. Tradução de Jaime Torrubiano Ripoll. Madrid: Reus, 1925. T. 1.

GROSSMAN, Vassili. Vida e destino. Tradução de Irineu Franco Perpetuo. Rio de Janeiro: Objetiva, 2014. [recurso digital]

HÄBERLE, Peter. A dignidade humana como fundamento da comunidade estatal. Tradução de Ingo Wolfgang Sarlet e Pedro Scherer de Mello Aleixo. In: SARLET, Ingo (Org.). Dimensões da dignidade: ensaios de filosofia do direito e direito constitucional. Porto Alegre: Livraria do Advogado, 2005.

HABERMAS, Jürgen. A constelação pós-nacional: ensaios políticos. Tradução de Márcio Seligman-Silva. São Paulo: Littera Mundi, 2001.

A inclusão do outro: estudos de teoria política. Tradução de George Sperber e Paulo Astor Soethe. São Paulo: Loyola, 2002.

Direito e democracia: entre facticidade e validade. Tradução de Flávio Beno Siebeneichler. Rio de Janeiro: Tempo Brasileiro, 1997, v. 1.

La modernidad, un proyecto incompleto. In: FOSTER, Hal (Ed.). La

Posmodernidad. Tradução de Jordi Fibla. 7. ed. Barcelona: Kairós, 2008. 
O discurso filosófico da modernidade: doze lições. Tradução de Luiz Sérgio Repa e Rodnei Nascimento. São Paulo: Martins Fontes, 2000.

Sobre a constituição da Europa. Tradução de Denilson Luis Werle, Luiz Repa e Rúrion Melo. São Paulo: UNESP, 2012.

Teoria e práxis: estudos de filosofia social. Tradução de Rúrion Melo. São Paulo: UNESP, 2011.

HANNUS, Gilles. Le paradoxe de l'État chez Emmauel Levinas, Cahiers d'études lévinassiennes: L’État de César, n. XIII, p. 42-65, 2015.

L'universel en question: noahisme et retour à partir des Lectures talmudiques d'Emmanuel Levinas, Cahiers d'études lévinassiennes: Pensée du retour, n. III, p. 41-71, 2004.

HARVEY, David. Condição pós-moderna: uma pesquisa sobre as origens da mudança cultural. Tradução de Adail Ubirajara Sobral e Maria Stela Gonçalves. 15. ed. São Paulo: Loyola, 2006.

HAYAT, Pierre. Emmanuel Levinas, éthique et société. Paris: Kimé, 1995.

Individualisme éthique et philosophie chez Levinas. Paris: Kimé, 1997.

La filosofia entre totalidade y trascendencia. In: LEVINAS, Emmanuel. Alteridad y trascendencia. Tradução de Miguel Lancho. Madrid: Arena Libros, 2014.

La liberté investie. Paris: Kimé, 2014.

. La philosophie entre totalité et transcendence. In: LEVINAS, Emmanuel.

Alterité et transcendance. 5. ed. Paris: Fata Morgana, 2014.

Preface. In: LEVINAS, Emmauel. Alterity and Transcendence. Tradução de Michael b. Smith. Londres: The Athlone Press, 1999. 
HELLER, Agnes; FEHÉR, Ferenc. A condição política pós-moderna. Tradução de Marcos Santarrita. Rio de Janeiro: Civilização Brasileira, 1998.

HENRIOT, Jacques. Note sur la date e le sens de l'apparition du mot "responsabilité", Archives de philosophie du droit, t. 22: la responsabilité, Paris, Sirey, p. 59-62, 1977.

HERZOG, Annabel. ¿Es el liberalismo “todo lo que necessitamos”? La política del surplus, de Levinas. In: DREIZIK, Pablo (Comp.). Levinas y lo político. Buenos Aires: Prometeo Libros, 2014.

HESPANHA, António Manuel. Cultura jurídica europeia: síntese de um milênio. Florianópolis: Boiteaux, 2005.

O caleidoscópio do direito: o direito e a justiça nos dias e no mundo de hoje. 2. ed. Coimbra: Almedina, 2009.

HOBBES, Thomas. Do cidadão. Tradução de Renato Janine Ribeiro. São Paulo: Martins Fontes: 2002.

Leviatã: ou a matéria, forma e poder de uma República eclesiástica e civil. Tradução de João Paulo Monteiro e Maria Beatriz Nizza da Silva. São Paulo: Martins Fontes, 2003.

HOBSBAWM, Eric. Era dos extremos: o breve século XX - 1914-1995. Tradução de Marcos Santarrita. 2. ed. São Paulo: Companhia das Letras, 2015.

HÖFFE, Otfried. La théorie du droit de Kelsen est-elle positiviste?, Cahiers de philosophie politique et juridique, n. 9: La philosophie du droit de Hans Kelsen, Caen, Centre de Publications de l'Université de Caen, 1986, p. 45-63, 1986.

HOLANDA, Sérgio Buarque de. Raízes do Brasil. 26. ed. São Paulo: Companhia das Letras, 2010. 
HOLDEN, Terence. Honneth, Kojève and Levinas on intersubjectivity and history, Continental Philosophy Review, New York, v. 49, issue 3, p. 349-369, 2016.

HONNETH, Axel. A teórica crítica da Escola de Frankfurt e a teoria do reconhecimento [entrevista com Olivier Voiriol], tradução de Rúrion Melo, Cadernos de filosofia alemã: crítica e modernidade, São Paulo, n. XVIII, p. 133-160, jul.-dez. 2011.

La sociedade del desprecio. Tradução de Francesc J. Hernàndez e Benno Herzog. Madrid: Trotta, 2011.

Luta por reconhecimento: a gramática moral dos conflitos sociais. 2. ed. Tradução de Luiz Repa. São Paulo: Editora 34, 2015.

Reconhecimento ou redistribuição? A mudança de perspectivas na ordem moral da sociedade. In: SOUZA, Jessé; MATTOS, Patrícia. Teoria crítica no século XXI. São Paulo, Annablume, 2007.

The other of justice: Habermas and the ethical challengeof postmodernism. In: WHITE, Stephen K. (Ed.) The Cambridge companion to Habermas. Cambridge: Cambridge University. 1995.

JESUS, Paulo. Autri-em-moi dans la phénoménologie de l'intersubjetctivé: Sartre, Merleau-Ponty, Levinas et la reconnaissance instable. In: Reconnaissance, identité et intégration social. Nanterre: Presses Universitaires de Paris Nanterrre, 2009, p. 4. Disponível em: <http://books.openedition.org/pupo/738>. Acesso em: 31 mai. 2017.

KAFKA, Franz. Na colônia penal. Tradução de Modesto Carone. São Paulo: Paz e Terra, 1996.

KANT, Immanuel. A metafísica dos costumes. 2. ed. rev. Tradução de Edson Bini. Bauru: EDIPRO, 2008.

À paz perpétua. Tradução de Marco Zingano. Porto Alegre: L\&PM, 2008. 
Fundamentação da metafísica dos costumes. Tradução de Paulo Quintela. Lisboa: Edições 70, 2007.

Ideia de uma história universal de um ponto de vista cosmopolita. Tradução de Rodrigo Naves e Ricardo Terra. 2. ed. São Paulo: Martins Fontes, 2004.

Resposta à pergunta: Que é o "Esclarecimento"? Tradução de Floriano de Sousa Fernandes. In: Immanuel Kant: textos seletos. 2. ed. Petrópolis: Vozes, 1985.

KASHIURA JR., Celso Naoto. Crítica da igualdade jurídica: contribuição ao pensamento jurídico marxista. São Paulo: Quartier Latin, 2009.

Sujeito de direito e capitalismo. São Paulo: Outras Expressões; Dobra Universitário, 2014.

KEARNEY, Richard. Postmodernisme et imagination éthique. In: GREISCH, Jean; ROLLAND, Jacques. (Dirs.) Emmanuel Levinas: l'éthique comme philosophie première (actes du colloque de Cerisy-la-Salle, 23 août- 2 septembre 1986). Paris: Cerf, 1993.

KEENAN, Dennis King. Reading Levinas reading Descartes' Meditations. In: KATZ, Claire; TROUT, Lara (Eds.). Emmanuel Levinas: Critical Assessments of Leading Philosophers. v. II: Levinas and the History of Philosophy. London: New York: Routledge, 2005.

KELSEN, Hans. Teoria pura do direito. Tradução de João Baptista Machado. 8. ed. São Paulo: WMF Martins Fontes, 2009.

KERSTING, Wolfgang. O fundamento de validade da Moral e do Direito em Kant. Tradução de Elisete Antoniuk. In: TRAVESSONI, Alexandre (Coord.). Kant e o Direito. Belo Horizonte: Mandamentos, 2009.

KLEIN, Joel Thiago. A resposta Kantiana à pergunta: que é esclarecimento?. ethic@ - An international journal for Moral Philosophy, Florianópolis, v. 8, n. 2, p. 211-227, ago. 2009. 
KOFMAN, Sarah. L'imposture de la beauté. In: CHALIER, Catherine. (Dir.) Le visage: dans la clarté, le secret demeure. Paris: Autrement, 1994.

KOJÈVE, Alexandre. Introdução à leitura de Hegel. Tradução de Estela dos Santos Abreu. Rio de Janeiro: Contraponto; EDUERJ, 2002.

KORELC, Martina. Sobre o direito a ser. In: CARBONARI, Paulo César; COSTA, José André da; DALMÁS, Giovana (Orgs.). Ética, educação e direitos humanos: estudos em Emmanuel Levinas. Passo Fundo: IFIBE, 2008.

LAFRANCE, Guy. L'humanisme juridique et le sujet de droit, Cahiers de philosophie politique et juridique, n. 14: Sujet de droit et objet de droit - L'homme est-il le seul sujet de droit?, Caen, Presses Universitaires de Caen, p. 7-30, 1993.

LATOUR, Bruno. Jamais fomos modernos. Tradução de Carlos Irineu da Costa. 2. ed. Rio de Janeiro: Ed. 34, 2009.

LE COZ, Pierre. Dignité et liberte: vers une contradiction insoluble?, Journal International de Bioéthique, Paris, v. 21, p. 15-27, 2010/3.

LEGROS, Robert. Levinas e les droits de l'autre homme, Cahiers d'études lévinassiennes: Pensée du retour, n. 3, p. 313-340, 2004.

LEITE, Flamarion Tavares. A responsabilidade em Kant e Levinas. Nomos - Revista do curso de Mestrado em Direito da UFC, Fortaleza, CE, v. 9/10, n. 1/2, p. 137-145, jan./dez. 1990/1991.

O conceito de Direito em Kant (na Metafísica dos Costumes). São Paulo: Ícone, 1996.

LESCOURRET, Marie-Anne. Emmanuel Levinas (1906-1995): un philosophe du XX siècle, Cités, Paris, n. 25, p. 13-24, 2006/1. 
LEVINAS, Emmanuel. A l'heure des nations. Paris: Minuit, 1988.

Alteridad y trascendencia. Tradução de Miguel Lancho. Madrid: Arena Libros, 2014.

Alterité et transcendance. 5. ed. Paris: Fata Morgana, 2014.

Alterity and Transcendence. Tradução de Michael b. Smith. Londres: The Athlone Press, 1999.

. Autrement qu'être ou au-delà de l'essence. La Haye: Martins

Nijhoff, 1974.

De Deus que vem à ideia. Tradução de Marcelo Fabri, Marcelo Luiz Pelizzoli

e Evaldo Antônio Kuiava. Coordenação e revisão de Pergentino Stefano Pivatto. 2. ed. Petrópolis: Vozes, 2008.

. De Dieu qui vient à l’idée. 2. ed. aument. Paris: VRIN, 2004.

De la evasión. 2. ed. Tradução de Isidro Herrera. Madrid: Arena, 2011.

. De la existência al existente. Tradução de Patricio Peñalver. Madrid: Arena Libros, 2000.

De l'existence à l'existant. 2. ed. aum. Paris: VRIN, 2004.

De l'oblitération: entretien avec Françoise Armengaud à propos de l'oeuvre de Sosno. 2. ed. Paris: La Différence, 1998.

Descobrindo a existência com Husserl e Heidegger. Tradução de Fernanda Oliveira. Lisboa: Piaget, 1997.

De otro modo que ser o más allá de la esencia. Tradução de Antonio Pintor Ramos. 4. ed. Salamanca: Sígueme, 2003. 
Deus, a morte e o tempo. Tradução de Fernanda Bernardo. Lisboa: 2015.

Difícil libertad: ensayos sobre el judaísmo. Tradução de Juan Haidar. Madrid: 2002.

Dios, la muerte y el tempo. Tradução de María Luisa Rodríguez Tapia. 3. ed. Madrid: Cátedra, 2005.

Do sagrado ao santo: cinco novas interpretações talmúdicas. Tradução de Marcos de Castro. Rio de Janeiro: Civilização Brasileira, 2001.

. Du sacré au saint: cinq nouvelles lectures talmudiques. Paris: Minuit, 1977.

El tiempo y el otro. Tradução de José Luis Pardo Toró. Barcelona: Paidós, 1993.

. En découvrant l'existence avec Husserl et Heidegger. 4. ed. corrig. Paris, VRIN, 2010.

Entre nós: ensaios sobre a alteridade. Tradução de Pergentino Stefano Pivatto, Evaldo Antônio Kuiava, Luiz Pedro Wagner e Marcelo Luiz Pelizolli. 3. ed. Petrópolis: Vozes, 2004.

Entre nous: essais sur le penser-à-l'autre. Paris: Grasset, 1991.

Entrevistas. In: POIRIÉ, François. Emmanuel Levinas: ensaio e entrevistas. Tradução de J. Guinsburg, Marcio Honorio de Godoy e Thiago Blumenthal. São Paulo: Perspectiva, 2007.

Épreuves d'une pensée (1935-1939). In: CHALIER, Catherine; ABENSOUR, Miguel (Orgs.). L'Herne: Emmanuel Levinas, Paris, 2006. 
Escritos inéditos 1: cuadernos del cautiverio, seguidos por escritos sobre el cautiverio y notas filosóficas diversas. Tradução de Miguel García-Baró. Madrid: Trotta, 2013.

Escritos inéditos 2: palavra y silencio y otros escritos. Tradução de Miguel García-Baró. Madrid: Trotta, 2015.

Ethique et Infini. Paris: Fayard/France Culture, 1982.

Ética e Infinito. Tradução de Jesús María Ayuso Diéz. 2. ed. Madrid: A. Machado Libros, 2000.

. Ética e infinito. Tradução de João Gama. Lisboa: Edições 70, 1982.

Être juif: suivi d'une lettre à Maurice Blanchot. Paris: Rivages, 2015.

Fuera del sujeto. Tradução de Roberto Ranz Torrejón e Cristina Jarilot Rodal. Madrid: Caparrós, 1997.

Humanisme de l'autre homme. Paris, Fata Morgana, s.d.

Humanismo do outro homem. Tradução de Pergentino S. Pivatto (Coord.). 4. ed. Petrópolis: Vozes, 2012.

. La etica. In: CASADO, Josefina; AGUDÍEZ, Pinar. (Comps.) El sujeto europeo. Tradução de María Luisa Feliú e Santiago Jorán. Madri: Pablo Iglesias, 1990.

L'au-delà du verset: lectures et discours talmudiques. Paris: Les Éditions de Minuit, 1982.

- L'essence spirituelle de l'antisémitisme (d'après Jacques Maritain). In: CHALIER, Catherine; ABENSOUR, Miguel (Orgs.). L'Herne: Emmanuel Levinas, Paris, 2006. 
Libertad y mandamento. In: La huella del otro. Tradução de Esther Cohen, Silvana Rabinovich e Manrico Montero. México: Taurus, 2001.

Libertad y mandato. In: La realidad y su sombra; Libertad y mandato; Transcendencia y altura. Tradução de Antonio Domínguez Leiva. Madrid: Minima Trotta, 2001.

. Liberté et commandement, Revue de Métaphysique et de Morale, a. 58, n. 3, p. 264-272, jul.-set./1953.

Los imprevistos de la historia. Tradução de Tania Checchi. Salamanca: Sígueme, 2006.

Les imprévus de l'historie. Paris: Fata Morgana, 2008.

. Más allá del versículo: lecturas y discursos talmúdicos. Tradução de Manuel Mauer. Buenos Aires: Lilmod, 2006.

Noms propres: Agnon, Buber, Celan, Delhomme, Derrida, Jabès, Kierkegaard, Lacroix, Laporte, Picard, Proust, Van Breda, Wahl. Montpellier: Fata Morgana, 1976.

Novas interpretações talmúdicas. Tradução de Marco de Castro. Rio de Janeiro: Civilização Brasileira, 2002.

- Paz y proximidad, tradução de Francisco Amoraga Montesinos e Andres Alonso Martos, Revista Laguna, n. 18, p. 143-154, mar./2006.

Quatre lectures talmudiques. Paris: Minuit, 2005.

- Quatro leituras talmúdicas. Tradução de Fábio Landa. São Paulo: Perspectiva, 2003.

Socialidade e dinheiro, Revista portuguesa de filosofia, Braga, v. 65, p. 641646, 2009. 
. Socialité et argent. In: CHALIER, Catherine; ABENSOUR, Miguel (Orgs.).

L'Herne: Emmanuel Levinas, Paris, 2006.

. Totalidade e Infinito: ensaio sobre a exterioridade. Tradução de José Pinto Ribeiro. Lisboa: Edições 70, 1980.

. Totalité et Infini: essai sur l'extériorité. Paris: Kluwer academic, 1991.

. Transcendance et hauteur. In: CHALIER, Catherine; ABENSOUR, Miguel (Orgs.). L'Herne: Emmanuel Levinas, Paris, 2006.

. Transcendencia y altura. In: La realidad y su sombra; Libertad y mandato; Transcendencia y altura. Tradução de Antonio Domínguez Leiva. Madrid: Minima Trotta, 2001.

LEVINAS, Emmanuel; LYOTARD, Jean-François. Autrement que savoir. In: LYOTARD, Jean-François. Logique de Levinas. Lagrasse: Verdier, 2015.

LÉVY, Benny. L’Alcebiade: introduction à la lecture de Platon. Laggrasse: Verdier, 2013.

LÉVY, Bernard-Henri. De Rosenzweig à Levinas. L'universel comme questiom, Cahiers d'études lévinassiennes: L'universel, n. VI, p. 247-275, 2007.

LEWIS-RODIS, Geneviève. Descartes e o racionalismo. Tradução de Jorge de Oliveira Paulista. Porto: Rés, 1979.

LIPOVETSKY, Gilles. El crepúsculo del deber: la ética indolora de los nuevos tiempos democráticos. Tradução de Juana Bignozzi. 5. ed. Barcelona: Anagrama, 2000.

La revolución de la autonomia. In: CASADO, Josefina; AGUDÍEZ, Pinar. (Comps.) El sujeto europeo. Tradução de María Luisa Feliú e Santiago Jorán. Madri: Pablo Iglesias, 1990. 
Pós-modernidade e hipermodernidade. In: FORBES, Jorge; REALE JR., Miguel; FERRAZ JR., Tercio Sampaio (Coords.). A invenção do futuro: um debate sobre a pós-modernidade e a hipermodernidade. Barueri: Manole, 2005.

LISPECTOR, Clarice. A hora da estrela. Rio de Janeiro: Rocco, 1998.

LIVCHITS, Darío. ¿Es el liberalismo suficiente para la dignidad humana? Sobre el desplazamiento en torno al liberalismo en Emmanuel Levinas. In: DREIZIK, Pablo (Comp.). Levinas y lo político. Buenos Aires: Prometeo Libros, 2014.

LOSTAO, Eduardo. La postmodernidad absoluta: intersubjetividad y ontología desde Totalidad e Infinito de Levinas. Granada: Comares, 2011.

LUHMANN, Niklas. Sociologia do Direito I. Tradução de Gustavo Bayer. Rio de Janeiro: Tempo Brasileiro, 1983.

Sociologia do Direito II. Tradução de Gustavo Bayer. Rio de Janeiro: Tempo Brasileiro, 1985.

LYOTARD, Jean-François. A condição pós-moderna. Tradução de Ricardo Corrêa Barbosa. 12. ed. Rio de Janeiro: José Oympio, 2009.

A fenomenologia. Tradução de Armindo Rodrigues. Lisboa: Edições 70, 1986.

Logique de Levinas. Lagrasse: Verdier, 2015.

MAIRAL, Javier Barraca. Emmanuel Levinas y la dignidad humana, a la luz del acontecimiento antropológico, Prisma jurídico, São Paulo, v. 7, n. 1, p. 59-80, jan./jun. 2008.

MALKA, Salomon. Emmanuel Levinas: la vida y la huella. Tradução de Alberto Sucasas. Madri: Trotta, 2006. 
MALLET, Marie-Louise. Écouter un visage? In: Rue Descartes: Emmanuel Levinas. Paris: PUF, 2006, p. 175-191.

MANDERSON, Desmond. Proximity, Levinas, and the soul of law. Quebec: McGillQueen's University Press, 2006.

MARCOS, Maria Lúcia. Reconhecimento e alteridade. In: MARCOS, Maria Lúcia; COUTINHO, Maria João; BARCELOS, Paulo. (Orgs.) Emmanuel Levinas: entre reconhecimento e hospitalidade. Lisboa: Edições 70, 2011.

MARION, Jean-Luc. La voix sans nom. Hommage - à partir - de Levinas. In: Rue Descartes: Emmanuel Levinas. Paris: PUF, 2006.

MARQUES, Cláudia Lima. Contratos no código de defesa do consumidor: o novo regime das relações contratuais: 5. ed. rev., atual. e ampl. São Paulo: Revista dos Tribunais, 2005.

MARQUES, Jordino. Descartes e sua concepção de homem. São Paulo: Loyola, 1993.

MARTINS, Rogério Jolins; LEPARGNER, Hubert. Introdução a Levinas: pensar a ética no século XXI. São Paulo: Paulus, 2014.

MARTOS, Andrés Alonso. Levinas - "Levinas". In: MARTÍNEZ, Alejandro; HENAR, Jacobo (Coords.) La postmodernidad ante el espejo. Zaragoza: Prensas Universitarias de Zaragoza, 2012.

MARX, Karl. Sobre a questão judaica. Tradução de Nélio Schneider e Wanda Caldeira Brant. São Paulo: Boitempo, 2010.

MATEUS, Samuel. A querela dos antigos e dos modernos: um mapeamento de alguns topoi, Cultura - Revista de História e Teoria das Ideias, Lisboa, v. 29, p. 1-17, 2012.

MATTÉI, Jean-François. A barbárie interior: ensaio sobre o i-mundo moderno. Tradução de Isabel Maria Loureiro. São Paulo: UNESP, 2002. 
MATURANO, Ángel Garrido. La encarnación del tiempo. Observaciones acerca de la relación entre tiempo y cuerpo a partir del pensamiento de E. Levinas. In: SOUZA, Ricardo Timm de; FARIAS, André Brayner de; FABRI, Marcelo Fabri (Orgs.). Alteridade e ética: obra comemorativa dos 100 anos de nascimento de Emmanuel Lévinas. Porto Alegre: EDIPUCRS, 2008.

MAZZUOLI, Valerio de Oliveira. Curso de direito internacional público. 3. ed. rev., atual. e ampl. São Paulo: Revista dos Tribunais, 2008.

MELO, Nelio Vieira de. A ética da alteridade em Emmanuel Levinas. Porto Alegre: EDIPUCRS, 2003.

Hermenêutica da solicitação e da libertação do sentido, Studium, Recife, v. 9, p. 7-29, 2002.

MELlO, Celso Antônio Bandeira de. O conteúdo jurídico do princípio da igualdade. 3. ed. São Paulo: Malheiros, 2010.

MINTOUME, Siméon Clotaire. L'éthique comme philosophie première ou la défense des droits de l'autre homme chez Emmanuel Levinas. Paris, L'Harmattan, 2011.

MONTORO, André Franco. Retorno à ética na virada do século. In: MARCILIO, Maria Luiza; RAMOS, Ernesto Lopes. Ética na virada do século: "busca do sentido da vida". São Paulo: LTr, 1997.

MOSĖS, Stéphane. Rosenzweig et Levinas: au-delà de la guerre. In: Rue Descartes: Emmanuel Levinas. Paris: PUF, 2006.

NEVES, A. Castanheira. O direito hoje e com que sentido? O problema atual da autonomia do direito. 3. ed. Lisboa: Piaget, 2012. 
O direito interrogado pelo tempo presente na perspectiva do futuro. In: NUNES, António José Avelãs; COUTINHO, Jacinto Nelson de Mirando (Coords.). O direito e o futuro: o futuro do direito. Coimbra: Almedina, 2008.

NOBRE, Marcos; REPA, Luiz. Breve apresentação. In: NOBRE, Marcos; REPA, Luiz (Orgs.). Habermas e a reconstrução da subjetividade. Campinas: Papirus, 2012.

OLIVEIRA, José Luiz de. Revolução como fundação no pensamento de Hannah Arendt, Cadernos de Ética e Filosofia Política, São Paulo, SP, n. 23, p. 37-51, jul. 2014.

OLIVEIRA, Manfredo Araújo de. Antropologia filosófica contemporânea: subjetividade e inversão teórica. São Paulo: Paulus, 2012.

OST, François. Contar a lei: as fontes do imaginário jurídico. Tradução de Paulo Neves. São Leopoldo: UNISINOS, 2007.

O tempo do direito. Lisboa: Piaget, 1999.

OUAKNIN, Marc-Alain. Lire aux éclats: éloge de la caresse. Paris: Seuil, 1994.

PACHECO, Ronilso; BINGEMER, Maria Clara Lucheti. Espiritualidade, ética e alteridade: de Etty Hillesum a Emmanuel Levinas. 2014, p. 3. Disponível em: <http://www.puc-rio.br/pibic/relatorio_resumo2014/relatorios_pdf/ctch/TEO/TEORonilso\%20Pacheco.pdf >. Acesso em: 12 set. 2017.

PACHUKANIS, E. B. Teoria geral do direito e marxismo. São Paulo: Acadêmica, 1988.

PELIZZOLI, Marcelo Luiz. Levinas: a reconstrução da subjetividade. Porto Alegre: EDIPUCRS, 2002.

Notas para compreender Levinas. In: SOUZA, Ricardo Timm de; FARIAS, André Brayner de; FABRI, Marcelo Fabri (Orgs.). Alteridade e ética: obra comemorativa dos 100 anos de nascimento de Emmanuel Levinas. Porto Alegre: EDIPUCRS, 2008. 
PEQUENO, Marconi. O sujeito dos direitos humanos. In: FERREIRA, Lúcia de Fátima Guerra; ZENAIDE, Maria de Nazaré Tavares; PEQUENO, Marconi (Orgs.). Direitos humanos na educação superior: subsídios para a educação em direitos humanos na filosofia. João Pessoa: UFPB, 2010.

PEREIRA, José Aparecido. Crítica de Levinas ao sujeito moral de Kant, PolymatheiaRevista De Filosofia, v. 4, n. 5, p. 99-111, 2009.

PESSOA, Fernando. Livro do desassossego. Rio de Janeiro: Tinta-da-china Brasil, 2016.

PIERUCCI, Antônio Flávio. Ciladas da diferença. 3. ed. São Paulo: Programa de PósGraduação em Sociologia da FFLCH-USP; Editora 34, 2013.

PIMENTA, Leonardo Goulart. Difícil justiça: a relação entre justiça e direito a partir do pensamento de Emmanuel Levinas. 2011. 195f. Tese (Doutorado) - Faculdade de Direito, Pontifícia Universidade Católica de Minas Gerais, Belo Horizonte, 2011.

PINTO, Cristiano Paixão Araujo. Modernidade, tempo e direito. Belo Horizonte: Del Rey, 2002.

PIVATTO, Pergentino Stefano. Advertência. In: RICOEUR, Paul. Outramente: leitura do livro Autrement qu'être ou au-delà de l'essence de Emmanuel Levinas. Tradução de Pergentino Stefano Pivatto. Petropólis: Vozes, 1999.

A ética de Levinas e o sentido do humano: crítica à ética ocidental e seus pressupostos, Veritas, Porto Alegre, v. 37, n. 147, p. 325-363, set.-1992.

Responsabilidade e justiça em Levinas. Veritas, Porto Alegre, RS, v. 46, n. 2, p. 217-230, jun. 2001.

POCHÉ, Fred. La culture de l'autre: une lecture postcoloniale d'Emmanuel Levinas. Lyon: Chronique Sociale, 2015 
PONZIO, Augusto. Sujet et alterité sur Emmanuel Levinas: suivi de deux dialogues avec Emmanuel Levinas. Paris: L’Harmattan, 1996.

PRADO, Adélia. Poesia reunida. 3. ed. Rio de Janeiro: Record, 2016.

PRATA, Henrique Moraes. Enfermidade e infinito: direitos da personalidade do paciente terminal. 2012. 194f. Tese (Doutorado) - Faculdade de Direito, Universidade de São Paulo, São Paulo, 2012.

PUCHTA, Friedrich. Encyclopédie. Tradução de Olivier Jouanjan. In: JOUANJAN, Olivier (Ed.) L'esprit de l'École historique du droit: textes inédits en français de F. C. von Savigny et G. F. Puchta; étude de Joachim Rückert. Annales de la Faculté de droit de Strasburg, nouvelle série, n. 7. Strasbourg: Presses Universitaires de Strasbourg, 2004.

REALE, Miguel. Introdução à filosofia. 4. ed. São Paulo: Saraiva, 2007.

RENAUT, Alain. Kelsen et le problème de l'autonomie du droit, Cahiers de philosophie politique et juridique, n. 9: La philosophie du droit de Hans Kelsen, Caen, Centre de Publications de l'Université de Caen, 1986, p. 9-21, 1986.

REY, Jean-François. Au nom de l'autre homme. Le statut de l'alterité dans de Droits de l'Homme. In: FERRÉOL, Gilles. (Ed.) Rapport à autri et personne citoyenne. Villeneuve-d-Aseq: Septentrion, 2002.

La mesure de l'homme: l'idée d'humanité dans la philosophie d'Emmanuel Levinas. Paris: Michalon, 2001.

Le maître absolu: Hegel et Hobbes dans la pensée d'Emmanuel Levinas, Revue internationale de philosophie, Paris, n. 235, p. 75-89, 2006/1.

RICOEUR, Paul. O si-mesmo como um outro. Tradução de Lucy Moreira Cesar. Campinas: Papirus, 1991. 
Outramente: leitura do livro Autrement qu'être ou au-delà de l'essence de Emmanuel Levinas. Tradução de Pergentino Stefano Pivatto. Petropólis: Vozes, 1999.

Percurso do reconhecimento. Tradução de Nicolás Nyimi Campanário. São Paulo: Loyola, 2016.

ROJAS, Rodrigo Montoya. Derechos humanos, diversidad y interdisciplinaridad, Revista Diversitas, São Paulo, SP. ano 2, n. 3, p. 401-460, set./2014-mar./2015.

Interculturalidad, racismo y negociaciones interculturales. Revista Diversitas, São Paulo, SP. ano 1, n. 1, p. 50-66, mar-set/2013.

ROJAS, Rodrigo Montoya. Movimentos indígenas na América do Sul: potencialidade e limites. In: BARSOTTI, Paulo; PERICÁS, Luiz Bernardo (Orgs.). América Latina: história, ideias e revolução. São Paulo: Xamã, 1998.

ROLLAND, Jacqus. Les intrigues du social, Esprit, n. 5, p. 150-161, mai. 1984 . L'humain dans l'homme: quelques notes, Esprit, n. 234 (7), p. 112-120, juillet 1997.

Notas. In: LEVINAS, Emmanuel. De la evasión. 2. ed. Tradução de Isidro Herrera. Madrid: Arena, 2011.

. Parcours de l'autrement: lecture d'Emmanuel Levinas. Paris: Presses Universitaires de France, 2000.

- Surenchère de l'éthique. In: LEVINAS, Emmanuel. Éthique comme philosophie première. Paris: Rivages Poche, 2015

. Un chemin de pensée. In: Rue Descartes: Emmanuel Levinas. Paris: PUF, 2006. 
ROSA, João Guimarães. A terceira margem do rio. In: Primeiras Histórias. Rio de Janeiro: Nova Fronteira, 2001.

ROSA, Luís Carlos Dalla. Educar para a sabedoria do amor: a alteridade como paradigma educativo. São Paulo: Paulinas, 2012.

ROSENFIELD, Denis L. Descartes e as peripécias da razão. São Paulo: Iluminuras, 1996.

ROSENZWEIG, Franz. La estrella de la redención. Tradução de Miguel Gracía-Baró. Salamanca: Sígueme, 1997.

ROUANET, Sergio Paulo. Regard de l'autre, regarde sur l'autre, Diógène, Paris, n. 193, p. 3-14, 2001/1.

RUIZ, Castor B. Emmanuel Levinas, alteridade e alteridades - questões da modernidade e a modernidade em questão. In: SOUZA, Ricardo Timm de; FARIAS, André Brayner de; FABRI, Marcelo Fabri (Orgs.). Alteridade e ética: obra comemorativa dos 100 anos de nascimento de Emmanuel Levinas. Porto Alegre: EDIPUCRS, 2008.

Os direitos humanos como direitos do outro. In: FERREIRA, Lúcia de Fátima Guerra; ZENAIDE, Maria de Nazaré Tavares; PEQUENO, Marconi (Orgs.). Direitos humanos na educação superior: subsídios para a educação em direitos humanos na filosofia. João Pessoa: UFPB, 2010.

RUBIÃO, Murilo. A fila. In: Obra completa. São Paulo: Companhia das Letras, 2010.

RUIZ, Pedro Enrique García. Geopolítica de la alteridad: Levinas y la filosofía de la liberación de E. Dussel, Isegoría: Revista de Filosofia Moral y Política, n. 51, p. 777-792, jul.-dez. 2014

SALANSKIS, Jean-Michel. L'émotion éthique: Levinas vivant I. Paris: Klincksieck, 2011. 
L'humanité de l'homme: Levinas vivant II. Paris: Klincksieck, 2011.

SALGADO, Joaquim Carlos. A ideia de justiça em Kant: seu fundamento na liberdade e na igualdade. 2. ed. Belo Horizonte: UFMG, 1995.

SALMORÁN, Rolando Tamayo. El sujeto del derecho. In: VALDÉS, Ernesto Garzón; LAPORTA, Francisco (Ed.). El derecho y la justicia. 2. ed. Madrid: Trotta, 2000.

SANTOS, Boaventura de Sousa. A crítica da razão indolente: contra o desperdício da experiência. 4. ed. São Paulo: Cortez, 2002.

SANTOS, Gislene Aparecida dos. A invenção do "ser negro": um percurso das ideias que naturalizaram a inferioridade dos negros. São Paulo: Educ/Fapesp; Rio de Janeiro: Pallas, 2005.

Nem crime, nem castigo: o racismo na percepção do judiciário e das vítimas de atos de discriminação, Revista do Instituto de Estudos Brasileiros, n. 62, p. 184-207, dez. 2015.

SANTOS, Leonel Ribeiro dos. Do paralogismo lógico da personalidade ao paradoxo moral da pessoa: génese e significado da antropologia moral kantiana. Studia Kantiana Revista da Sociedade Kant Brasileira, Santa Maria, RS, n. 11, p. 7-40, dez. 2011.

SANTOS, Milton. O espaço do cidadão. 7. ed. São Paulo: EdUSP, 2007.

SARLET, Ingo Wolfgang. As dimensões da dignidade da pessoa humana: construindo uma compreensão jurídico-constitucional necessária e possível. In: SARLET, Ingo (Org.). Dimensões da dignidade: ensaios de filosofia do direito e direito constitucional. Porto Alegre: Livraria do Advogado, 2005.

Dignidade (da pessoa) humana, mínimo existencial e justiça constitucional: algumas aproximações e alguns desafios, Revista do CEJUR/TJSC: Prestação Jurisdicional, Florianópolis, v. 1, n. 1, p. 29-44, dez. 2013. 
SAVIGNY, Friedrich Carl Von. Derecho romano actual. Tradução de Jacinto Mesía e Manuel Poley. Madrid: Góngora, 1878, t. I.

SAYÃO, Sandro Cozza. Levinas e o argumento do infinito: um diálogo com Descartes. Princípios, Natal, RN, v. 18, n. 30, p. 143-162, jul./dez. 2011.

SCHAUER, Frederick. Playing by the rules: a philosophical examination of rule based decision-making in law and in life. Oxford: Clarendon Press, 2002.

SCHWARCZ, Lilia Moritz. Nem preto nem branco, muito pelo contrário: cor e raça na sociabilidade brasileira. São Paulo: Claro Enigma, 2012.

SCHWARCZ, Lilia Moritz; STARLING, Heloisa Murgel. Brasil: uma biografia. São Paulo: Companhia das Letras, 2015.

SCHWARZ, Roberto. As ideias fora do lugar. In: Ao vencedor as batatas: forma literária e processo social nos inícios do romance brasileiro. 5. ed. São Paulo: Duas cidades; Ed. 34, 2007.

SILVA, Cláudia Maria Fidalgo da. A noção de responsabilidade na filosofia moral kantiana. Estudos Kantianos, Marília, SP, v. 2, n. 1, p. 143-168, jan./jun. 2014.

SILVA, Franklin Leopoldo e. Descartes: a metafísica da modernidade. 2. ed. São Paulo: Moderna, 2005.

Felicidade: dos filósofos pré-socráticos aos contemporâneos. São Paulo: Claridade, 2007.

O outro. São Paulo: WMF Martins Fontes, 2012.

SILVA NETO, Sertório de Amorim e. O estopim de uma querela: Chares Perrault e sua homenagem ao século de Luís XIV, Cadernos de Ética e Filosofia Política, São Paulo, SP, n. 23, p. 93-108, jul. 2014. 
SODRÉ, Olga. Percurso filosófico para a concepção de alteridade. Síntese, Belo Horizonte, MG, v. 34, n. 109, p. 157-184, 2007.

SOSOË, Lukas. La distinction de l'être e du devoir-être dans la Théorie Pure du Droit, Cahiers de philosophie politique et juridique, n. 9: La philosophie du droit de Hans Kelsen, Caen, Centre de Publications de l'Université de Caen, 1986, p. 67-81, 1986.

SOUZA, Jessé. A construção social da subcidadania: para uma sociologia política da modernidade periférica. Belo Horizonte: UFMG; Rio de Janeiro: IUPERJ, 2006.

Ralé brasileira: quem é e como vive, 2009, p.

SOUZA, Ricardo Timm de. Em torno à diferença: aventuras da alteridade na complexidade da cultura contemporânea. Rio de Janeiro: Lumen Juris, 2008.

Sentido e alteridade: dez ensaios sobre o pensamento de Emmanuel Levinas.

2. ed. Porto Alegre: EDIPUCRS, 2009.

Sujeito, ética e história: Levinas, o traumatismo infinito e a crítica do pensamento ocidental. Porto Alegre: EDIPUCRS, 1995.

O tempo e a máquina do tempo: estudos de filosofia e pós-modernidade. Porto Alegre: EDIPUCRS, 1998.

Pensar e instaurar a paz - o pensamento de Rosenzweig e Levinas no núcleo dos acontecimentos do século XX. In: SUSIN, Luiz Carlos et. al. (Orgs.). Éticas em diálogo: Levinas e o pensamento contemporâneo - questões e interfaces. Porto Alegre: EDIPUCRS, 2003.

Por uma pedagogia da alteridade: repensando a educação com Levinas. In: CARBONARI, Paulo César; COSTA, José André da; DALMÁS, Giovana (Orgs.). Ética, educação e direitos humanos: estudos em Emmanuel Levinas. Passo Fundo: IFIBE, 2008. 
Reflexões sobre a questão do sofrimento a partir de Émile Cioran e Emmanuel Levinas, Veritas, Porto Alegre, v. 37, n. 147, p. 387-395, set.-1992.

- Totalidade e desagregação: sobre as fronteiras do pensamento e suas alternativas. Porto Alegre: EDUPUCRS, 1996.

STONE, Matthew. Life beyond law: questioning a return to origins. In: STONE, Matthew; WALL, Illan Rua; DOUZINAS, Costas. New critical legal thininking: law and the political. Abingdon: Routledge, 2012.

SUCASAS, Alberto. El rostro y el texto: la unidad de ética y hermenéutica. Barcelona: Anthropos, 2001.

SUSIN, Luiz Carlos. Levinas e a reconstrução da subjetividade, Veritas, Porto Alegre, v. 37, n. 147 , p. 365-377, set.-1992.

O homem messiânico: uma introdução ao pensamento de Emmanuel Levinas. Porto Alegre: EST; Petrópolis: Vozes, 1984.

TERRA, Ricardo. Kant \& o direito. Rio de Janeiro: Jorge Zahar, 2004.

THOMAS, Yan-Patrick. Acte, agent, société: sur l'homme coupable dans la pensée juridique romaine, Archives de philosophie du droit, t. 22: la responsabilité, Paris, Sirey, p. 63-83, 1977.

TINLAND, Franck. La notion de sujet de droit dans la philosophie politique de Th. Hobbes, J. Locke et J.-J. Rousseau, Archives de philosophie du droit, t. 34: le sujet de droit, Paris, Sirey, p. 51-66, 1990.

TODOROV, Tzvetan. O espírito das luzes. Tradução de Mônica Cristina Corrêa. São Paulo: Barcarolla, 2008.

TOURAINE, Alain. Crítica da modernidade. Tradução de Elia Ferreira Edel. 9. ed. Petrópolis: Vozes, 2009. 
VATTIMO, Gianni. El consumidor consumido. In: CASADO, Josefina; AGUDÍEZ, Pinar. (Comps.) El sujeto europeo. Tradução de María Luisa Feliú e Santiago Jorán. Madri: Pablo Iglesias, 1990.

VAZ, Henrique C. de Lima. Escritos de filosofia VII: raízes da modernidade. São Paulo: Loyola, 2002.

Nota histórica sobre o problema filosófico do "outro". In: Escritos de filosofia VI: ontologia e história. São Paulo: Loyola, 2001.

VILA-CHÃ, João. Enigma da transcendência: elementos para uma ontologia do exílio segundo E. Levinas. In: SUSIN, Luiz Carlos et. al. (Orgs.). Éticas em diálogo: Levinas e o pensamento contemporâneo - questões e interfaces. Porto Alegre: EDIPUCRS, 2003.

VILLEY, Michel. A formação do pensamento jurídico moderno. Tradução de Claudia Berliner. São Paulo: Martins Fontes, 2005.

Critique de la pensée juridique moderne (douze autres essais). Paris: Dalloz, 1976.

Esquisse historique sur le mot responsable, Archives de philosophie du droit, t. 22: la responsabilité, Paris, Sirey, p. 45-58, 1977.

Leçons d'historie de la philosophie du droit. Paris: Dalloz, 1962.

WARAT, Luis Alberto. A pureza do poder: uma análise crítica da teoria jurídica. Florianópolis: UFSC, 1983.

A rua grita Dionísio! Direitos humanos da alteridade, surrealismo e cartografia. Tradução de Vívian Alves de Assis, Júlio Cesar Marcellino Jr. e Alexandre Morais da Rosa. Rio de Janeiro: Lumen Juris, 2010. 
WATSON, Richard. Descartes: el filósofo de la luz. Tradução de Carlos Gardini. Barcelona: Vergara, 2003.

WIEACKER, Franz. História do direito privado moderno. Tradução de António Manuel Hespanha. 2. ed. Lisboa: Fundação Calouste Gulbenkian, 1980.

ZIELINSKI, Agata. Levinas: la responsabilité est sans porquoi. Paris: PUF, 2004. 